Supporting Information for

\title{
Self-Reducible Conjugated Microporous Polyaniline for Long-Term Selective Cr(VI) Detoxication Driven by Tunable Pore Dimension
}

Jie Chen ${ }^{a}$, Yubing Wang $^{b}$, Changshen Ye $e^{c}$ Wei Lyu ${ }^{d}$, Jinwei Zhu ${ }^{b}$, Wei Yan ${ }^{*}, b$ and Ting Qiu ${ }^{*}, c$

${ }^{a}$ College of Environment and Resources, Fuzhou University, Fuzhou, Fujian 350116, P.R. China

${ }^{\mathrm{b}}$ Department of Environmental Science and Engineering, Xi'an Jiaotong University, Xi'an 710049, P.R. China

${ }^{\mathrm{c}}$ College of Chemical Engineering, Fuzhou University, Fuzhou 350116, Fujian, China

${ }^{\mathrm{d}}$ State Key Laboratory for Modification of Chemical Fibers and Polymer Materials, College of Materials Science and Engineering, Donghua University, Shanghai 201620, P.R. China

\footnotetext{
Corresponding Author

*yanwei@xjtu.edu.cn (Prof. Wei Yan)

*tingqiu@fzu.edu.cn (Prof. Ting Qiu)
} 


\section{Contents}

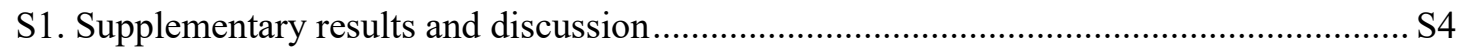

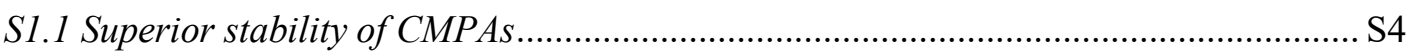

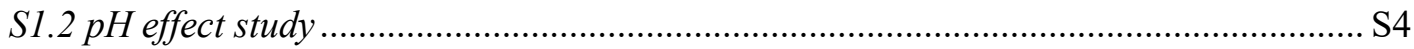

S1.3 Information of pseudo-first order and pseudo-second order kinetic model ................ S4

S1.4 Information of Langmuir and Frenudlich model................................................... S5

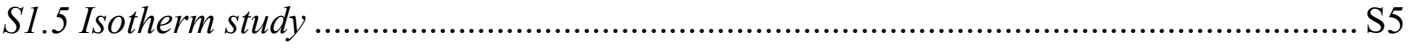

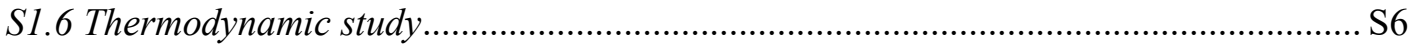

S1.7 Photographs of $\mathrm{Cr}(\mathrm{VI})$ solution during repeating use............................................... S6

S1.8 TEM-EDS and TEM discussion of CMPA networks after adsorption........................ S7

S1.9 FTIR discussion of CMPA networks after adsorption .................................................. S7

S1.10 Solid state UV/Vis spectra discussion of CMPA networks after adsorption ............. S7

S1.11 TGA discussion of CMPA networks after adsorption ................................................ 7

S1.12 SEM/EDX discussion of CMPA networks after repeating use .................................. 7

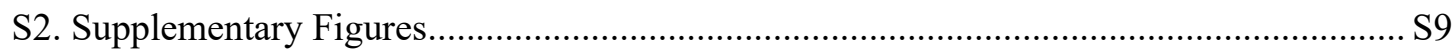

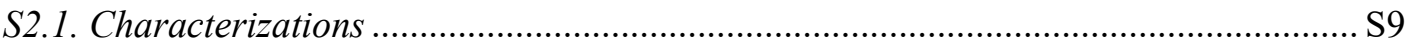

S2.1.1 Polyaniline structure in CMPA networks confirmed by SS UV/Vis NIR study.... S9

S2.1.2 Polyaniline structure in CMPA networks confirmed by XPS study.................. S10

S2.1.3 Successful polymerization and tuning via our BXJ method of CMPA networks

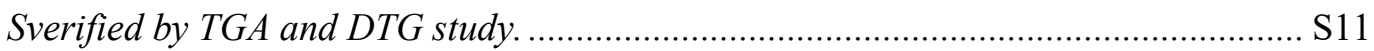

S2.1.4 Conjugated microporous polymer structure in CMPA networks confirmed by SEM study (with gelation morphology and property)........................................................... $\mathrm{S} 12$

S2.1.5 Successful polymerization and tuning via our BXJ method of CMPA networks verified by FTIR study.

S2.1.6 Successful polymerization and tuning via our BXJ method of CMPA networks verified by $S S^{13}$ C CP/MAS NMR study .................................................................... S14

S2.1.7 Amorphous CMPA networks confirmed by PXRD study ................................. S18

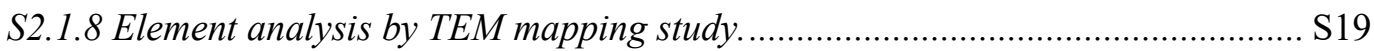

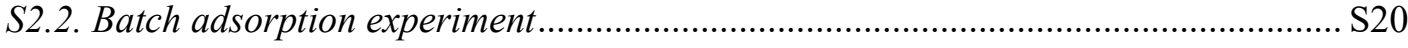

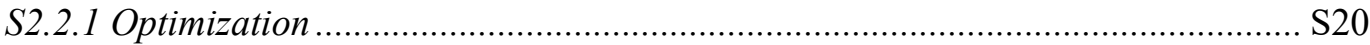

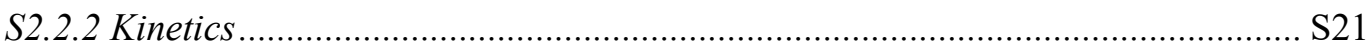

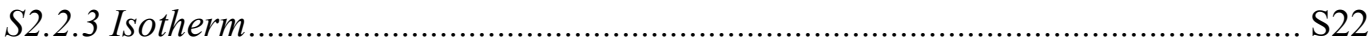


S2.2.4 Repeating use

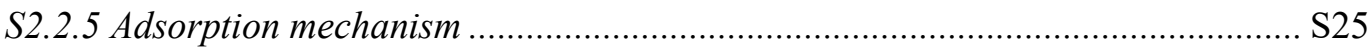

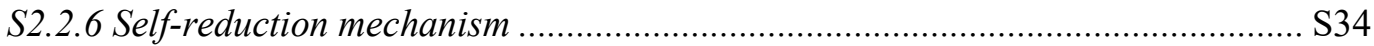

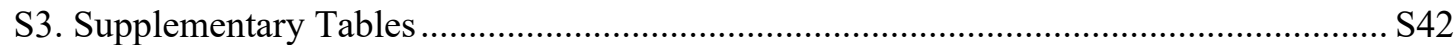

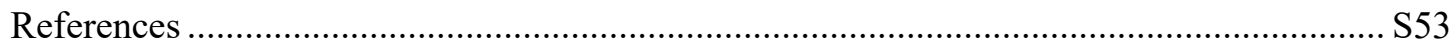




\section{S1. Supplementary results and discussion}

\section{S1.1 Superior stability of CMPAs}

The obtained polymers were insoluble in common organic solvents including toluene, THF, dioxane, dichloromethane, chloroform, ethanol, methanol and acid/base solution ( $2 \mathrm{M} \mathrm{HCl}$ or $2 \mathrm{M} \mathrm{NaOH}$ ), exhibiting their robustness and high degree of cross-linking, which were also confirmed by thermal gravimetric analysis (TGA) and differential thermogravimetric analysis (DTG) results (high thermal stabilities at even $300^{\circ} \mathrm{C}$, as shown in Figure S3 and Figure S4) ${ }^{1-2}$ The advanced stability, compared to that of common MOFs and COFs, also promises our CMPA networks keeping their high microporosity after workup involving washing steps in acid and base solution. BXJ method allows our CMPA networks to show macroscopic gelation property in the reaction solution, which was also seen in CMP-1 synthesis. ${ }^{3}$ The foam-like featured morphologies of three polymers were observed due to the later phase separation of the oligomers during synthesis, assuring the obtaining of rich microporous structures, as shown in Figure S5. ${ }^{1-2}$ After adsorption of $\mathrm{Cr}(\mathrm{VI})$, robustness of our networks was exhibited, again, from the TGA, SEM and FTIR study that there is no evident deterioration on the thermostability and foam morphology even after interacting with high concentration of $\mathrm{Cr}(1000 \mathrm{mg} / \mathrm{L} \mathrm{Cr}(\mathrm{VI})$ at initial), indicating the change caused by $\mathrm{Cr}(\mathrm{VI})$ on CMPA structure was mild (Figure S19-21; Figure S28). ${ }^{1}$

\section{S1.2 pH effect study}

To acquire the optimized condition for $\mathrm{Cr}$ adsorption, the effect of solution $\mathrm{pH}$ on the adsorption capacity was conducted, and the results were shown in Figure S13(a). It shows that the removal efficiencies of three CMPAs for $\mathrm{Cr}(\mathrm{VI})$ were highly $\mathrm{pH}$-dependent. Gradual decrease of efficiency happened with increase of $\mathrm{pH}$. The $\mathrm{pH}=2$ was therefore determined as the optimized condition and applied in the followed adsorption study. The point of zero charge analysis through zeta potential study was then conducted to understand the surface charge effects, and the results were depicted in Figure S13(b). The $\mathrm{pH}$ of the point of zero charge for these three CMPAs was estimated to be 8.12, 5.15 and 4.48, respectively, while the zeta potentials showed a gradually decrease with the increase of solution $\mathrm{pH}$. The positive charged nature was contributed by the doping-dedoping property of PANI, in which the polymer would be doped by the $\mathrm{H}^{+}$when the polymer was treated in low $\mathrm{pH}$ solution, and would be gradually dedoped when increased the solution $\mathrm{pH}$. Therefore, the similar trend of adsorption capacity vs. $\mathrm{pH}$ with that of doping degree (or amount of positive charge on the chain) vs. pH confirmed that one possible mechanism for the $\mathrm{Cr}(\mathrm{VI})$ adsorption (mainly presented as $\mathrm{HCrO}_{4}^{-}$or $\mathrm{Cr}_{2} \mathrm{O}_{7}^{2-}$ at $\mathrm{pH}>2$ ) may be the electrostatic interaction (or doping as counter ions). This results in some $\mathrm{Cr}$ adsorption for CMPA-3, even though the pore size of CMPA-3 was not favorable for $\mathrm{Cr}$ capture.

\section{S1.3 Information of pseudo-first order and pseudo-second order kinetic model}

\section{(1) Pseudo-first order model}

The equation of pseudo-first order model is $Q_{t}=Q_{m, c}\left(1-\exp \left(-k_{1} t\right)\right)$, where $Q_{t}(\mathrm{mg} / \mathrm{g})$ is the adsorption/detoxication capacity of the CMPA networks at time $t(\mathrm{~min})$, which can be calculated from the equation $Q_{t}=\left(c_{0}-c_{t}\right) V / m$, where $m(\mathrm{mg})$ is the adsorbent mass, $V$ (L) is the volume of $\mathrm{Cr}(\mathrm{VI})$ solution, $c_{0}$ and $c_{t}(\mathrm{mg} / \mathrm{L})$ are the $\mathrm{Cr}(\mathrm{VI})$ concentration at adsorption/detoxication time $t=0 \mathrm{~min}$ and $t=t \mathrm{~min}$, while $Q_{m, c}(\mathrm{mg} / \mathrm{g})$ is the maximum 
adsorption/detoxication capacity calculated from the model. $k_{1}\left(\mathrm{~min}^{-1}\right)$ indicates the adsorption/detoxication constant of pseudo-first order model. $R^{2}$ suggests the regression constants.

\section{(2) Pseudo-second order model}

The equation of pseudo-second order model is $Q_{t}=k_{2} Q_{m, c}^{2} t /\left(1+k_{2} Q_{m, c} t\right) . k_{2}(\mathrm{~g} / \mathrm{mg} / \mathrm{min})$ indicates the adsorption/detoxication constant of pseudo-second order model. $R^{2}$ suggests the regression constants. $h(\mathrm{mg} / \mathrm{g} / \mathrm{min})$ is the initial adsorption/detoxication rate calculated from the equation of $h=k_{2} Q_{m, c}{ }^{2}$.

\section{S1.4 Information of Langmuir and Frenudlich model}

\section{(1) Langmuir model}

The expression of Langmuir model can be shown as $Q_{e}=K_{L} Q_{m} c_{e} /\left(1+K_{L} C_{e}\right)$, where the $Q_{e}(\mathrm{mg} / \mathrm{g})$ could be obtained from the adsorption/detoxication capacity when the equilibrium reached, and $c_{e}(\mathrm{mg} / \mathrm{L})$ could be acquired from the equilibrium concentration of $\mathrm{Cr}(\mathrm{VI})$ when the equilibrium reached at different $\mathrm{Cr}(\mathrm{VI})$ solution with initial concentration $\left(c_{0}\right)$. Therefore, the $Q_{e}$ can be calculated as $Q_{e}=\left(c_{0}-c_{e}\right) V / m$ with adsorbent mass of $m(\mathrm{mg})$ and volume $V(\mathrm{~L})$ of $\mathrm{Cr}(\mathrm{VI})$ solution, while the $K_{L}(\mathrm{~L} / \mathrm{mg})$ is the Langmuir constant indicating the adsorption/detoxication affinity between CMPA networks and Cr ions. $Q_{m}(\mathrm{mg} / \mathrm{g})$ shows the maximum adsorption capacity of CMPA networks for $\mathrm{Cr}(\mathrm{VI})$.

\section{(2) Frenudlich model}

The equation of Frenudlich model is $Q_{e}=K_{F} c_{e} e^{1 / n}$, where the $K_{F}\left(\mathrm{~L}^{1 / n} \mathrm{mg}^{1 / \mathrm{n}-1} \mathrm{~g}^{-1}\right)$ is the Frenudlich constant showing the adsorption/detoxication capacity, while $1 / n$ indicates the adsorption/detoxication difficulty of CMPA networks towards $\mathrm{Cr}(\mathrm{VI})$. Good adsorption/detoxication can be occurred if $0.1<1 / n<0.5$.

\section{S1.5 Isotherm study}

It can be clearly observed in Figure S15 that no visible pink color from $\mathrm{Cr}$ (III) can be seen after the detoxication of CMPA networks during the isotherm investigation. The isotherm data were fitted with Langmuir model and Frenudlich model shown above, and the fitted parameters were shown in Table 3 in the manuscript. The co-relationship between adsorption isotherm data and model was good, indicating a single layer adsorption of $\mathrm{Cr}(\mathrm{VI}) / \mathrm{Cr}(\mathrm{III})$ on CMPA networks. The very different adsorption capacities between these three polymers were observed, even though with similar polyaniline structure and $\mathrm{N}$-riched atoms in the chain, confirming the successful tuning of adsorption capacity by adjusting the pore size via linker length.

In Figure S17(g), there is not extensive adsorption or reduction effect of PANI when the dosage is less than $1 \mathrm{~g} / \mathrm{L}$, while the pink colour, resulted from $\mathrm{Cr}(\mathrm{III})$, can be clearly observed when the applied dosage is larger than $1 \mathrm{~g} / \mathrm{L}$, suggesting the poor storage capacity of PANI for $\mathrm{Cr}(\mathrm{III})$. Still 127.5 $\mathrm{mg} / \mathrm{L}$ of $\mathrm{Cr}(\mathrm{III})$ was detected in the $1.5 \mathrm{~g} / \mathrm{L}$ PANI-treated solution with the initial concentration of $200 \mathrm{mg} / \mathrm{L}$ even though the detoxication capacity of $\mathrm{Cr}(\mathrm{VI})$ of $133.1 \mathrm{mg} / \mathrm{g}$ was reached as shown in Figure S17 (e). It suggests that the main mechanism of detoxication of the PANI is reduction, which also confirmed by pH effect study shown in Figure S17 (d). The color, thereafter, gradually reduced 
with the dosage due to the increased adsorption sites of $\mathrm{Cr}(\mathrm{III})$. As its counterparts- our CMPA networks, as shown in Figure S15, show no colour even in low dosage (dosage of $1.5 \mathrm{~g} / \mathrm{L}$ ) or in high initial concentration (i.e. whose initial concentration is larger than $200 \mathrm{mg} / \mathrm{L}$ ), greatly exhibiting the advantage of large surface area and fine-tuned micropores. These interesting properties make our CMPA networks real Cr scavengers instead of just reducing $\mathrm{Cr}(\mathrm{VI})$ into $\mathrm{Cr}(\mathrm{III})$, like PANI.

\section{S1.6 Thermodynamic study}

The vant Hoff equation was exploited to acquire the thermodynamic parameters, i.e. Gibbs free energy change $(\Delta G, \mathrm{~kJ} / \mathrm{mol})$, entropy change $(\Delta S, \mathrm{~J} / \mathrm{mol} / \mathrm{K})$ and enthalpy change $(\Delta H, \mathrm{~kJ} / \mathrm{mol})$. The detailed equation was shown as follows, ${ }^{4}$

$\Delta G=-R T \ln K_{L}$,

$\Delta G=\Delta H-T \Delta S$,

where $K_{L}$ is the Langmuir constant calculated from Langmuir isotherm model, which is acquired in Table 3 in the manuscript; $R$ is the gas constant, which is usually shown as $8.314 \mathrm{~J} / \mathrm{mol} / \mathrm{K} ; T$ is the temperature. The calculation was performed as follows. Specifically, (1) the $\Delta G$ of the CMPAs for $\mathrm{Cr}(\mathrm{VI})$ at each specific temperature (i.e. $288 \mathrm{~K}, 298 \mathrm{~K}, 308 \mathrm{~K}$ and $318 \mathrm{~K}$ ) could be calculated from the equation $\Delta G=-R T \ln K_{L}$, where $K_{L}$ could be fitted from Langmuir model through the isotherm study (noted the unit of $K_{L}$ is $\mathrm{L} / \mathrm{mg}$ in the table, which should be converted to $\mathrm{L} / \mathrm{g}$ herein; in other words, $K_{L}$ should be multiplied by 1000 before use). (2) Group data of $\Delta G \sim T$ could be acquired. (3) Noted $\Delta G=\Delta H-T \Delta S$; the parameters of $\Delta H$ and $\Delta S$ could be therefore acquired through the liner fitting of $\Delta G$ vs. $T$, and the intercept shows the value of $\Delta H$, while the slope multiplied by (-1) indicates the value of $\Delta S$.

The results calculated from the procedures were shown in Table S3. The negative values of $\Delta G$ of each sample showed the spontaneous nature of the adsorption for $\mathrm{Cr}(\mathrm{VI})$, while the positive values of $\Delta H$ and $\triangle S$ of each CMPA network confirmed that the adsorption of $\mathrm{Cr}(\mathrm{VI})$ on our CMPAs was endothermic and endoentropic. Additionally, the small enthalpy change value $(\Delta H)$ in the adsorption of CMPA-1 and CMPA-2 for Cr(VI) were seen, indicating the temperature influence on the $\mathrm{Cr}(\mathrm{VI})$ adsorption for these two samples was mild, and the adsorption may be conducted through a physical way; a much higher enthalpy change value $(\Delta H)$ in the adsorption of CMPA-3 for $\mathrm{Cr}(\mathrm{VI})$ were shown, showing the $\mathrm{Cr}(\mathrm{VI})$ adsorption to CMPA-3 would be much more easily influenced by the temperature, and the adsorption may undergo in a different chemisorption manner. This keeps confirming our hypothesis on the contribution of molecular-size-recognition mechanism on CMPA1 and CMPA-2 through the pore selection (which was a physical adsorption). As for CMPA-3, a different adsorption manner, i.e. doping (through the zeta potential study and effect of $\mathrm{pH}$ investigation in Section S1.2) played a more important role in the adsorption, while the pore size of CMPA-3 was not favourable for $\mathrm{Cr}$ capture through molecular-size-recognition mechanism.

\section{S1.7 Photographs of Cr(VI) solution during repeating use}

From Figure S18, the solution was clean and colorless without pink color caused by $\mathrm{Cr}$ (III) or yellow color resulted from $\mathrm{Cr}(\mathrm{VI})$ before $4^{\text {th }}$ runs. The solution started to show pink color after the $5^{\text {th }}$ run, and to turn deeper and deeper with the repeating run goes (It seems the solution in $10^{\text {th }}$ cycle was presented as black colour. However, it was due to the accumulation of pink colour, and the 
solution was pink in nature). However, the concentration of $\mathrm{Cr}(\mathrm{VI})$ was still undetectable. This clearly shows the adsorption saturation of $\mathrm{Cr}(\mathrm{III})$ and self-reduction properties of our CMPA networks, without any treatment.

\section{S1.8 TEM-EDS and TEM discussion of CMPA networks after adsorption}

From Figure S22-24, it could be clearly seen that, interestingly, the signal of $\mathrm{K}^{+}$, a competing ion with $\mathrm{Cr}(\mathrm{III})$, was very weak on the used CMPA networks. It can be therefore deduced that the selective adsorption happened in our CMPA networks when adsorbing the $\mathrm{Cr}(\mathrm{III})$, which may thanks to the suitable and well-defined pore size for Cr(III) adsorption of our CMPA networks.

In Figure S26, it can be noticed that the micropores were greatly eliminated by $\mathrm{Cr}(\mathrm{VI})$, indicating the useful function of micropore for the $\mathrm{Cr}$ storage. On the other hand, interestingly, some lattice fringes arose in CMPA-1 after the interaction with $\mathrm{Cr}(\mathrm{VI})$. This, however, could not be explained at current stage.

\section{S1.9 FTIR discussion of CMPA networks after adsorption}

In Figure S28, no extensive changes were found in the FTIR spectra after treated with $1000 \mathrm{mg} / \mathrm{L}$ $\mathrm{Cr}$, suggesting the robustness of our CMPA networks. The changes could be noted are at the peaks at around 1200 and $3500 \mathrm{~cm}^{-1}$. The rising of the peak at around $1200 \mathrm{~cm}^{-1}$ was resulted from the doping of $\mathrm{HCrO}_{4}^{-}$in the acid solution; ${ }^{2}$ the rising of the peak at around $3500 \mathrm{~cm}^{-1}$ was caused by the hydroxyls brought by $\mathrm{HCrO}_{4}^{-}$and the water medium. In addition, the peak intensity of $1580 \mathrm{~cm}^{-}$ ${ }^{1}$ increased compared to that at $1490 \mathrm{~cm}^{-1}$, suggesting the gradually doping of $\mathrm{HCrO}_{4}^{-}$on the CMPA networks. ${ }^{5}$ In other words, doping is another important adsorption mechanism for our CMPA networks to capture $\mathrm{Cr}(\mathrm{VI})$, apart from pore adsorption.

\section{S1.10 Solid state UV/Vis spectra discussion of CMPA networks after adsorption}

In Figure S34, doping of CMPA networks in acid solution was achieved, obtaining a narrower bandgap in the first run (Figure S34(d-f)), while the bandgap enlarged in a small extent after 10 run interaction of $200 \mathrm{mg} / \mathrm{L} \mathrm{Cr}(\mathrm{VI})$, confirming the structure change during the self-healing process. However, the decrease degree of the bandgap enlargement was quite small, which was also confirmed by TGA and XPS study below. These all suggest that our self-healing CMPA networks could be applied in the long-term $\mathrm{Cr}(\mathrm{VI})$ detoxication without any reactivation or chemicals.

\section{S1.11 TGA discussion of CMPA networks after adsorption}

In Figure S35-S36, the high thermostability for three CMPA networks maintained after 10 runs with $200 \mathrm{mg} / \mathrm{L} \mathrm{Cr}(\mathrm{VI})$, indicating the highly cross-linked structures were kept during the recycling. These results can also explain why the COD of the solution did not increase during the self-healing of CMPA networks.

\section{S1.12 SEM/EDX discussion of CMPA networks after repeating use}

We performed SEM/EDX study on the CMPAs after 10 cycling use to get insight the Cr content left in the polymers, and the results were listed in Figure S41 and Table S13 shown below. Noted the $\mathrm{Cr}$ contents left in the polymers and solution at each cycle have been well calculated through an ICP method (results shown in Figure 3(d) in the manuscript). 
$\mathrm{Cl}$ elements were introduced by the $\mathrm{HCl}$ treatment when adjusting the $\mathrm{pH}$ of $\mathrm{Cr}(\mathrm{VI})$ solution; trace of $\mathrm{Pd}$ and $\mathrm{Br}$ were seen in the EDS, which was due to the incomplete coupling of $-\mathrm{Br}$ and $-\mathrm{NH}_{2}$ and difficult removal of $\mathrm{Pd}$ from the micropores; $\mathrm{Cr}$ elements shows weight ratios of $\mathrm{Cr}$ to polymer for CMPA-1, CMPA-2 and CMPA-3 of 1.253:1, 1.170:1 and 0.968:1 (or $1253 \mathrm{mg} \mathrm{Cr} / \mathrm{g}$ CMPA, 1170 $\mathrm{mg} \mathrm{Cr} / \mathrm{g}$ CMPA and $968 \mathrm{mg}$ Cr/g CMPA for CMPA-1, CMPA-2 and CMPA-3, respectively), which fitted quite well with those acquired by the ICP method (see Figure 3(d) in the manuscript), in which the accumulated adsorption capacities reaching 1026.13, 998.13, $931.93 \mathrm{mg} / \mathrm{g}$ of $\mathrm{Cr}$ were acquired by CMPA-1, CMPA-2 and CMPA-3, respectively after 10 cycles. The slightly higher value of the results acquired from SEM/EDS than those from the ICP method suggests that the $\mathrm{Cr}(\mathrm{VI})$ was mainly adsorbed on the outer layer of CMPAs, while the inner CMPA was unavailable for Cr. Specifically, SEM/EDS showed limited element estimation function because only the elements on the CMPA surface could be detected. As such, element distribution on the surface could be reflected by this method. While the $\mathrm{Cr}$ content as well as the accumulated adsorption capacities calculated from ICP technical reflected well the concentration distribution of Cr on the overall CMPAs, which additionally took the inner CMPA into consideration. We can therefore assumed the $\mathrm{Cr}(\mathrm{VI})$ was mainly adsorbed on the outer layer of CMPAs because the concentration of $\mathrm{Cr}(\mathrm{VI})$ on the surface (acquired from SEM/EDX) was higher than that on the overall CMPAs. Even so, the difference between these two data was quite small, suggesting the usage of our CMPA networks for Cr storage was high.

To fully reflect the Cr adsorption on our CMPAs, we kept using the ICP technical to calculated the accumulated adsorption capacities on the CMPA networks, which was summarized in Figure 3(d) in the manuscript. 


\section{S2. Supplementary Figures}

\section{S2.1. Characterizations}

S2.1.1 Polyaniline structure in CMPA networks confirmed by SS UV/Vis NIR study.
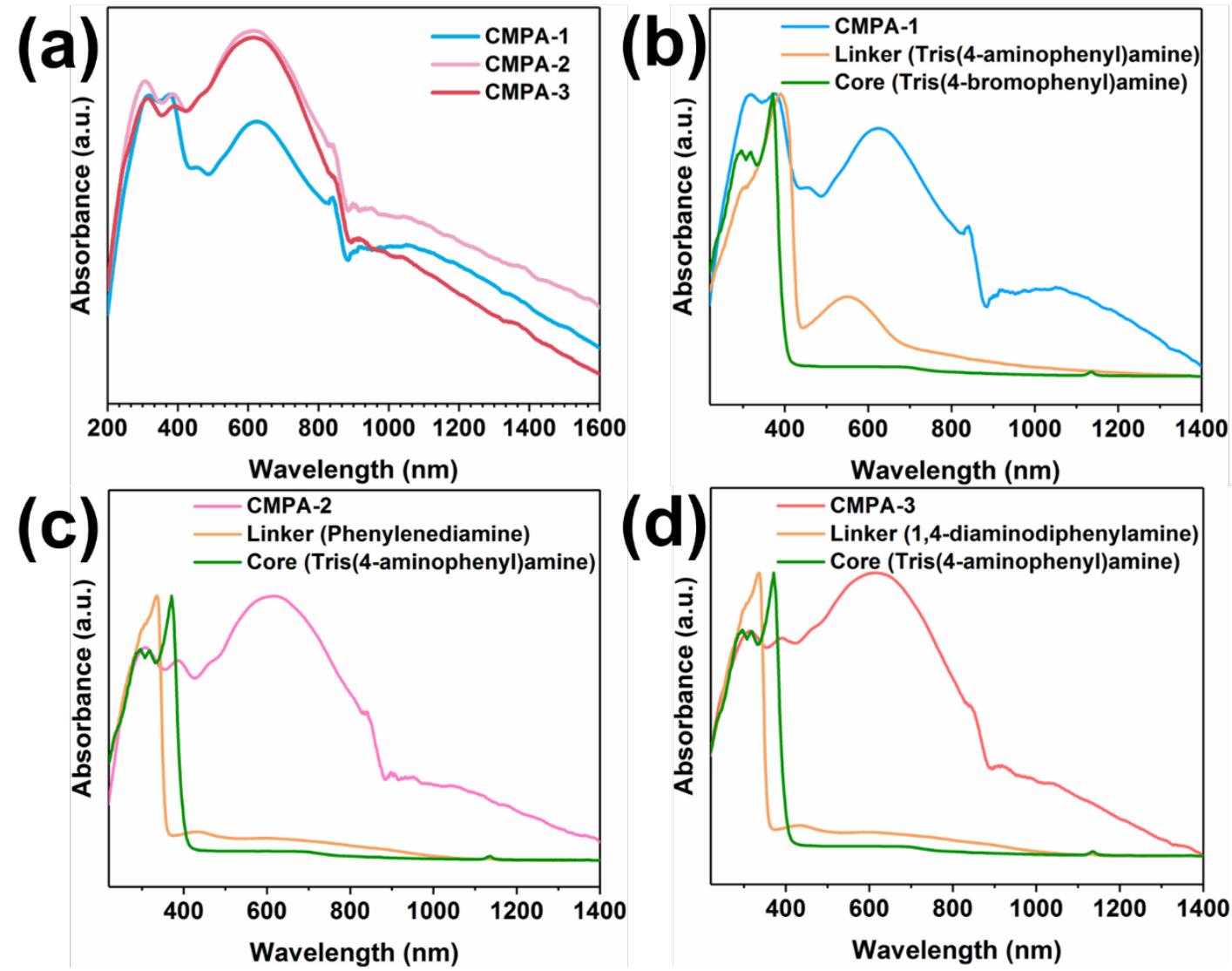

Wavelength $(\mathrm{nm})$

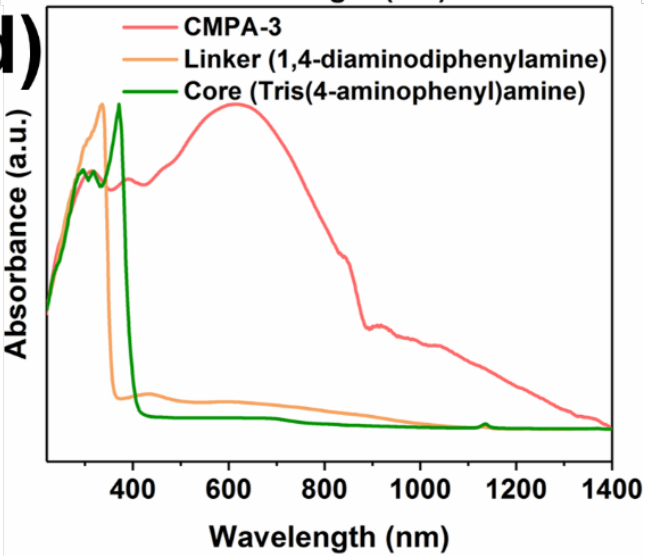

Figure S1 SS UV/Vis NIR spectra of the CMPA networks (a) and their related cores and linkers (b-d). 
S2.1.2 Polyaniline structure in CMPA networks confirmed by XPS study.
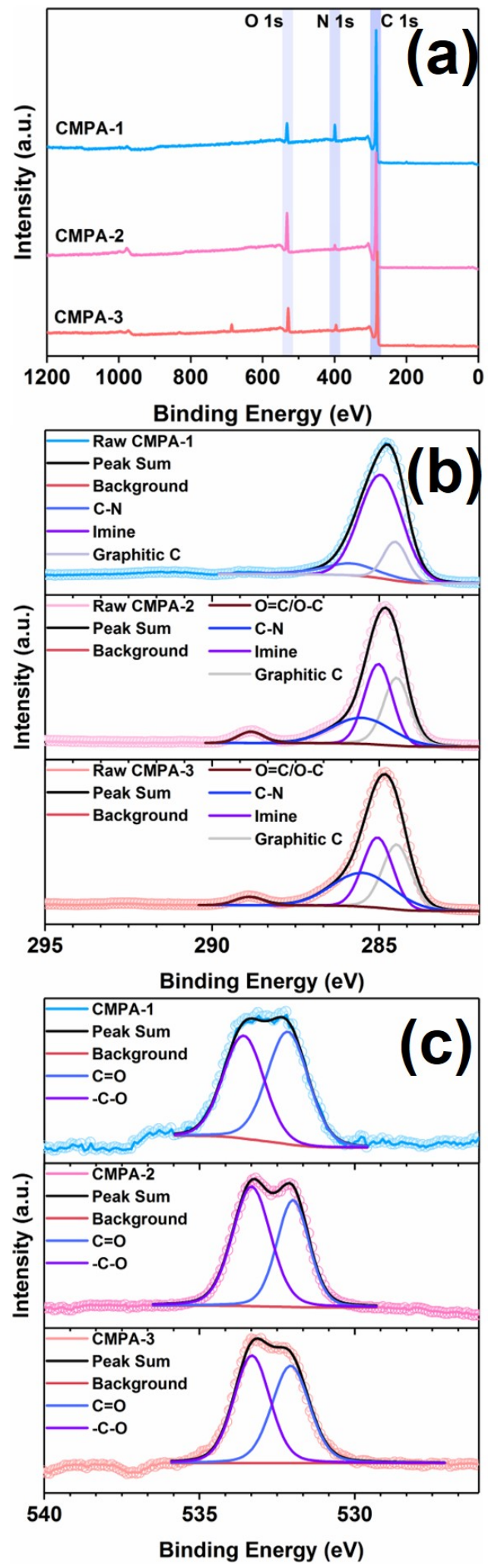

Figure S2 Full scan of XPS spectra (a), C 1s (b) and O 1s (c) XPS spectra of the CMPA networks; details were shown in Table S1. 
S2.1.3 Successful polymerization and tuning via our BXJ method of CMPA networks verified by TGA and DTG study.

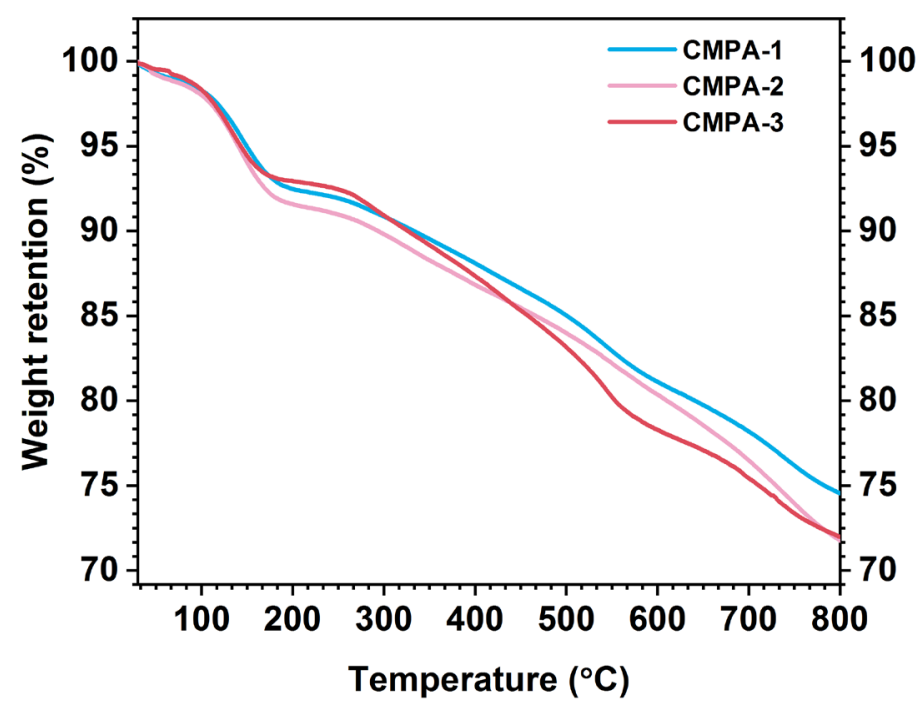

Figure S3 TGA curve of the CMPA networks.

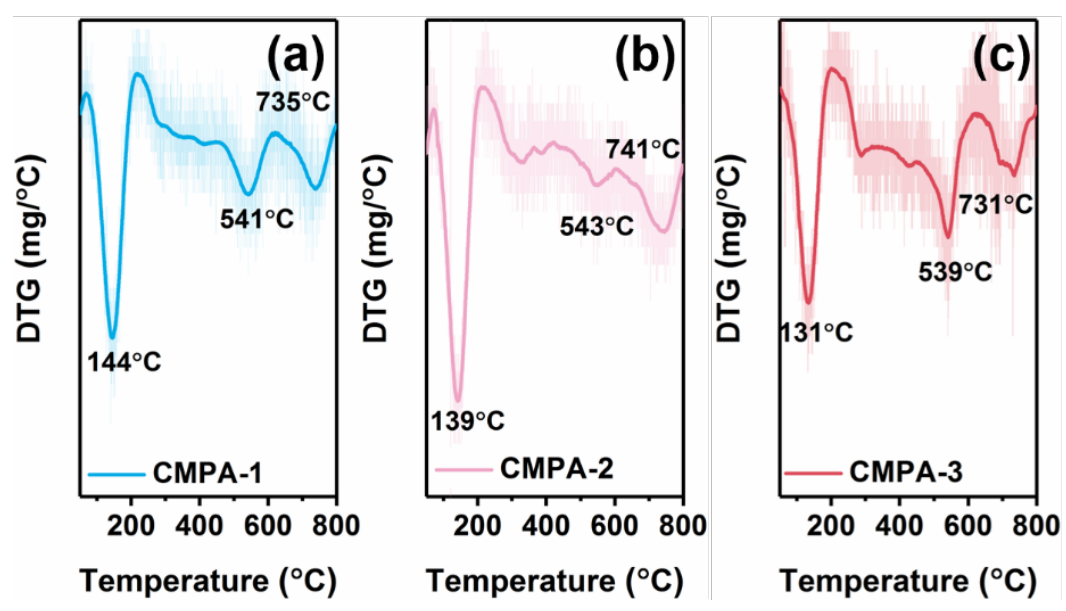

Figure S4 DTG curve of the CMPA networks (CMPA-1, a; CMPA-2, b; CMPA-3, c). 
S2.1.4 Conjugated microporous polymer structure in CMPA networks confirmed by SEM study (with gelation morphology and property).

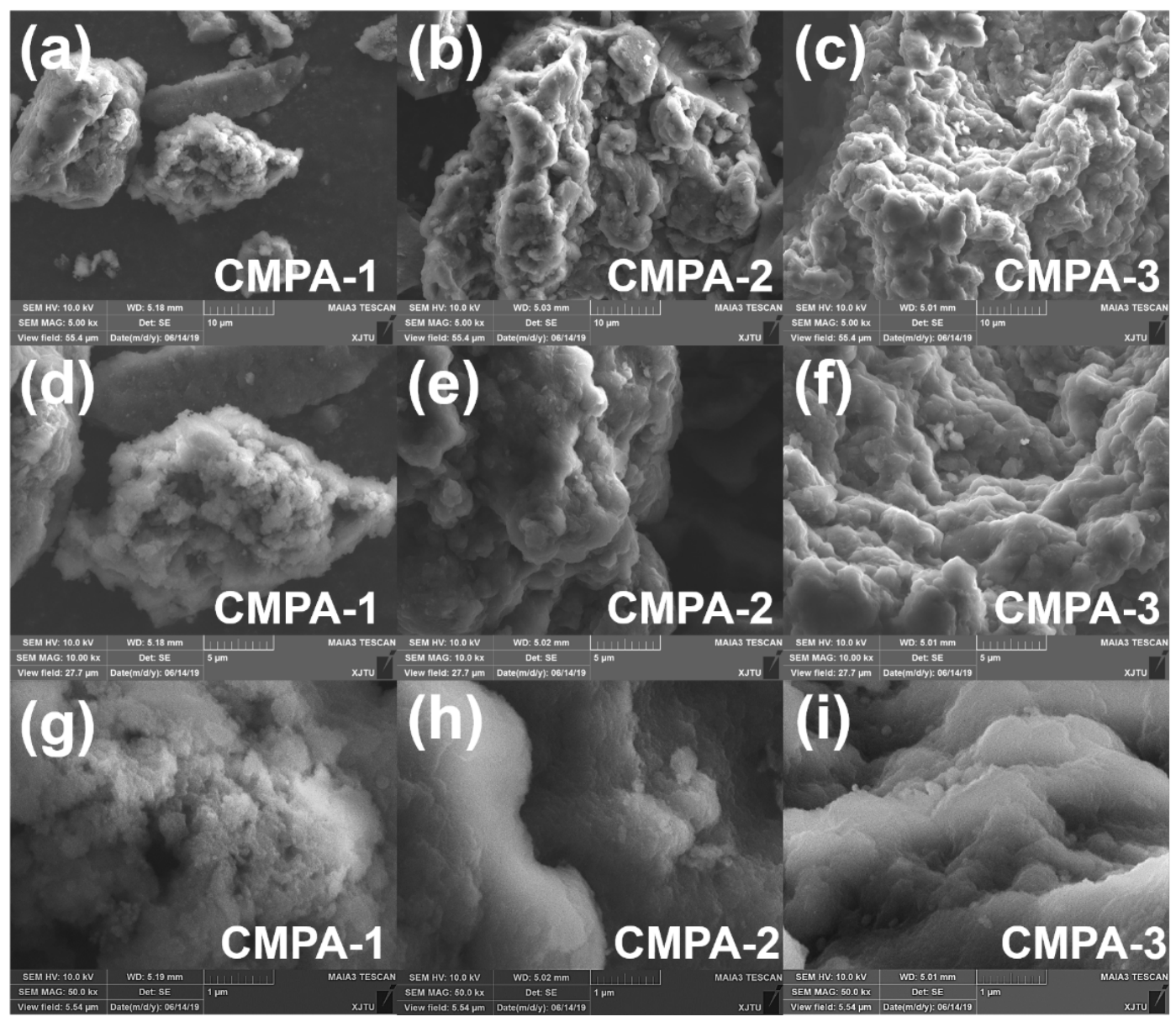

Figure S5 SEM images of the CMPA networks in large scale (a-c, scale bar of $10 \mu \mathrm{m}$ ), medium scale (d-f, scale bar of $8 \mu \mathrm{m})$ and small scale (g-i, scale bar of $1 \mu \mathrm{m})$. 
S2.1.5 Successful polymerization and tuning via our BXJ method of CMPA networks verified by FTIR study.
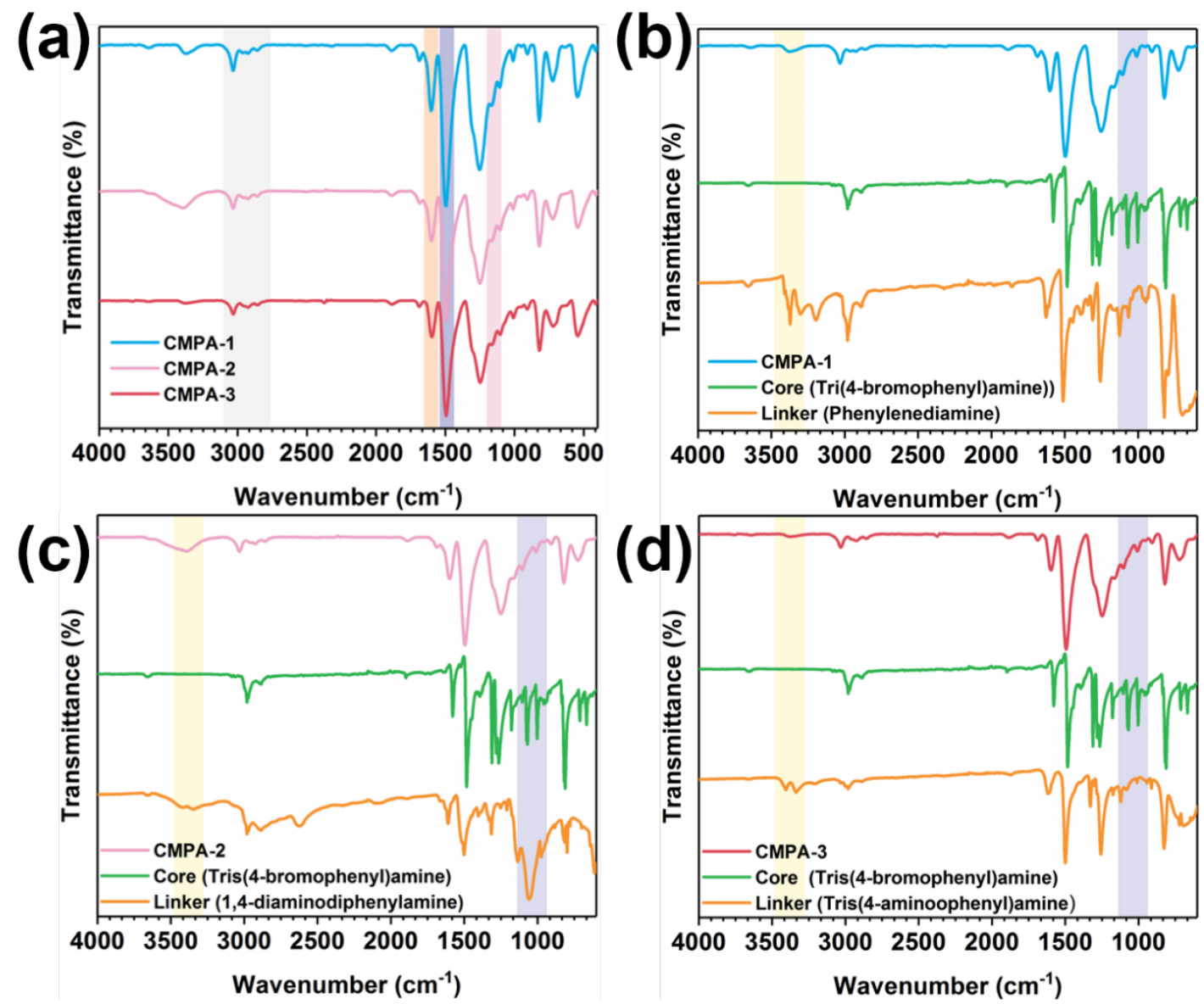

Figure S6 FTIR spectra of the CMPA networks (a) and their related cores and linkers (b-d) (the yellow stripe highlighted the band assigned to $-\mathrm{NH}_{2}$, while the purple one showed the band ascribed to $\mathrm{C}-\mathrm{Br}$ in (b-d)). 
S2.1.6 Successful polymerization and tuning via our BXJ method of CMPA networks verified by SS ${ }^{13} \mathrm{C} C P / M A S$ NMR study.

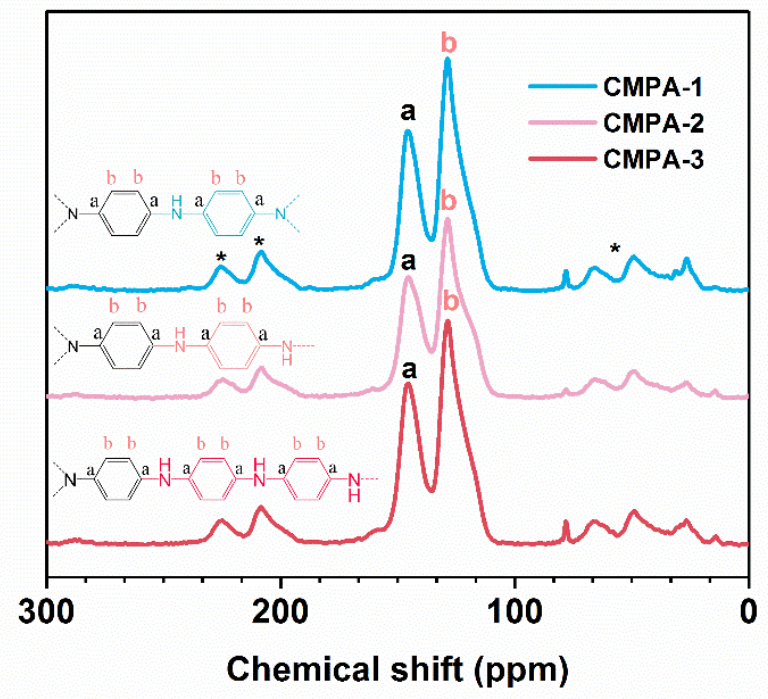

Figure S7 SS ${ }^{13} \mathrm{C} \mathrm{CP} / \mathrm{MAS}$ NMR spectra of the CMPA networks (asterisks mark spinning side bands). 


\section{ChemNMR ${ }^{13} \mathrm{C}$ Estimation}

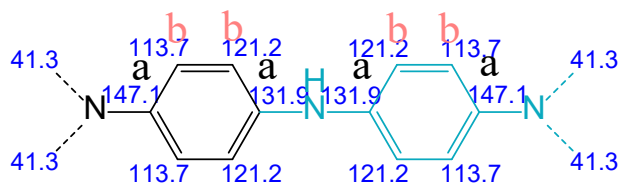

Estimation quality is indicated by color: good, medium, rough
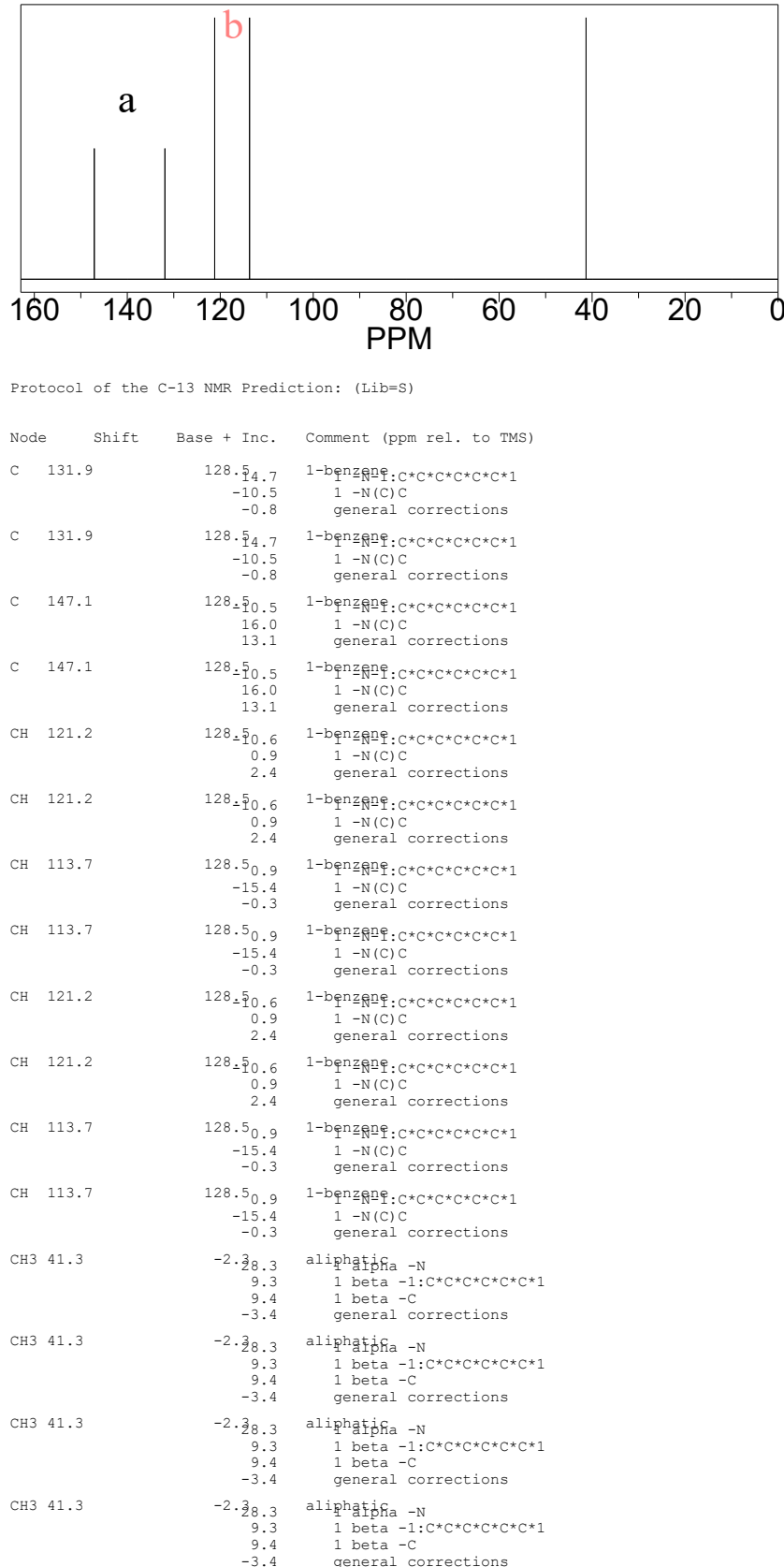

Figure S8 Calculation results of the ChemNMR ${ }^{13} \mathrm{C}$ for the CMPA-1 by ChemDraw Professional 17.0 . 


\section{ChemNMR ${ }^{13} \mathrm{C}$ Estimation}

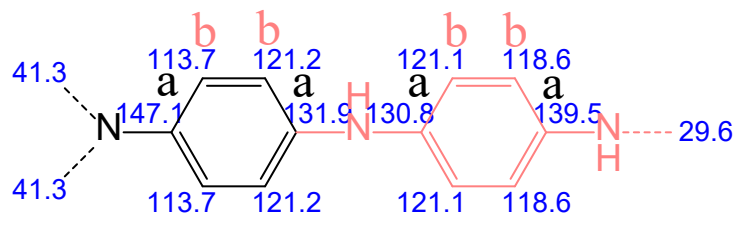

Estimation quality is indicated by color: good, medium, rough

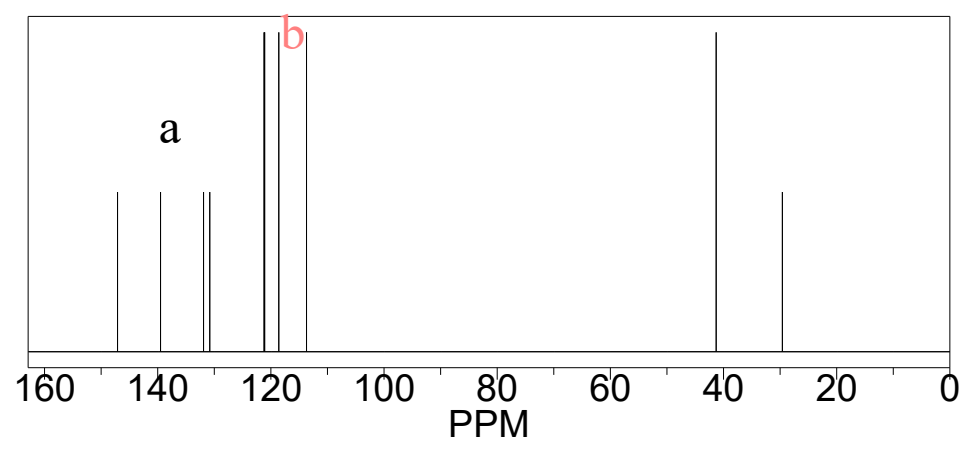

$$
\begin{aligned}
& \text { Protocol of the C-13 NMR Prediction: (Lib=S) } \\
& \text { Node Shift Base + Inc. Comment (ppm rel. to TMS) }
\end{aligned}
$$

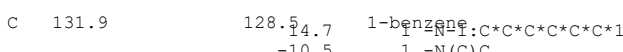

$$
\begin{aligned}
& \begin{array}{rl}
-10.5 & 1-\mathrm{N}(\mathrm{C}) \mathrm{C} \\
-0.8 & \text { general corrections }
\end{array}
\end{aligned}
$$

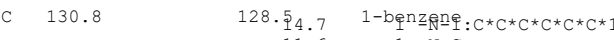

$$
\begin{aligned}
& -11.6 \quad 1-\mathrm{N}-\mathrm{C} \\
& 128=50.5 \quad 1-\text { beqnzennene: }: C * C * C * C * C * C * 1 \\
& \begin{array}{ll}
16.0 & 1-\mathrm{N}(\mathrm{C}) \mathrm{C} \\
13.1 & \text { general corrections }
\end{array} \\
& 128.50 .5 \quad 1-\mathrm{b} \text { en } \\
& \begin{array}{rl}
15.0 & 1-\mathrm{N}-\mathrm{C} \\
6.5 & \text { general corrections }
\end{array} \\
& 128=\$ 0.6 \quad 1 \text {-bennzenne }: C^{*} C^{*} C^{*} C^{*} C^{*} C^{*} \\
& 0.9 \quad 1-\mathrm{N}(\mathrm{C}) \mathrm{C} \\
& 2.4 \text { general corrections } \\
& 128=\$ 0.6 \quad 1-\text { be } 1 \text { nz } \\
& \text { general corrections } \\
& \mathrm{CH} \quad 113.7 \\
& \mathrm{CH} \quad 118.6 \\
& \mathrm{CH} \quad 121.2 \\
& \mathrm{CH} \quad 121.1 \\
& \mathrm{CH} \quad 113.7 \\
& \mathrm{CH} \quad 118.6 \\
& \text { CH3 } 41.3 \\
& \text { CH3 } 41.3 \\
& \text { CH3 } 29.6 \\
& \begin{array}{rc}
128.50 .9 & 1-\text { benzenene } \\
-15.4 & 1-\mathrm{N}(\mathrm{C}) \mathrm{C} \\
-0.3 & \text { general corrections }
\end{array} \\
& \begin{array}{rc}
128.50 .9 & 1-\text { benzenene } \\
-15.4 & 1-\mathrm{N}(\mathrm{C}) \mathrm{C} \\
-0.3 & \text { general corrections }
\end{array}
\end{aligned}
$$

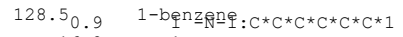

$$
\begin{aligned}
& 1-\mathrm{N}-\mathrm{C} \\
& \text { general corrections }
\end{aligned}
$$

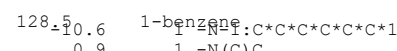

$$
\begin{aligned}
& 0.9 \quad 1-\mathrm{N}(\mathrm{C}) \mathrm{C} \\
& \text { general corrections }
\end{aligned}
$$

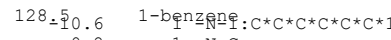

$$
\begin{aligned}
& \begin{array}{l}
1-\mathrm{N}-\mathrm{C} \\
\text { general corrections }
\end{array} \\
& \begin{array}{rr}
128.50 .9 & 1 \text {-benzenene: } C^{*}{ }^{*}{ }^{*} C^{*} C{ }^{*} C{ }^{*} C * 1 \\
-15.4 & 1-N(C) C
\end{array} \\
& -15.4 \quad 1-\mathrm{N}(\mathrm{C}) \mathrm{C} \\
& -0.3 \text { general corrections }
\end{aligned}
$$

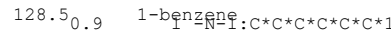

$$
\begin{aligned}
& \text { general corrections } \\
& \text { aliphateipifa }-\mathrm{N} \\
& 1 \text { beta }-1: C{ }^{*} C^{*} C^{*} C^{*} C * C * 1 \\
& \text { general corrections } \\
& 1 \text { beta }-1: C{ }^{*} C{ }^{*} C{ }^{*} C^{*} C{ }^{*} C * \\
& 1 \text { beta }-C \\
& \text { aliphątipifa }-\mathrm{N} \\
& 1 \text { beta }-1: C{ }^{\star} C^{\star} C^{\star} C^{\star} C^{\star} C{ }^{\star} \\
& \begin{array}{l}
1 \text { beta }-1: \mathrm{C}^{*} \mathrm{C}^{*} \mathrm{C}^{\star} \mathrm{C}^{\star} \mathrm{C}^{\star} \mathrm{C}^{\star} \\
\text { general corrections }
\end{array}
\end{aligned}
$$

Figure S9 Calculation results of the ChemNMR ${ }^{13} \mathrm{C}$ for the CMPA-2 by ChemDraw Professional 17.0 . 
ChemNMR ${ }^{13} \mathrm{C}$ Estimation

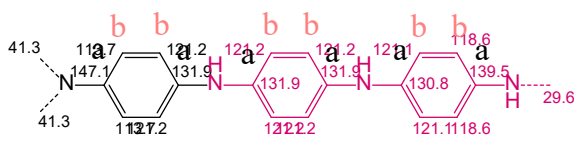

Estimation quality is indicated by color: good, medium, rough

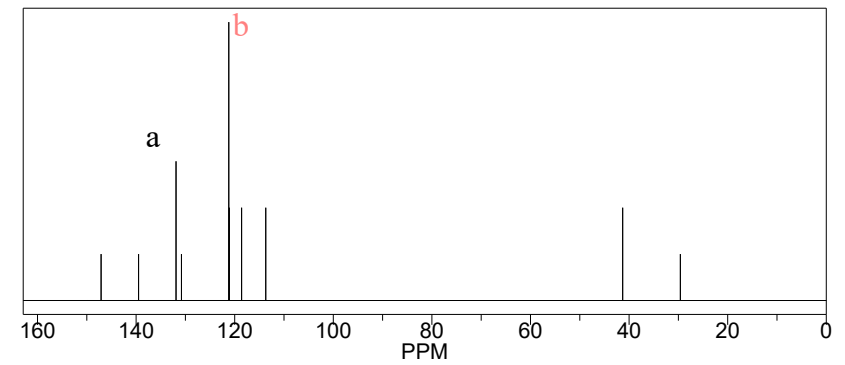

Protocol of the C-13 NMR Prediction: (Lib=S)

\begin{tabular}{|c|c|c|c|}
\hline Node & Shift & Base + Inc. & Comment (ppm rel. to TMS) \\
\hline c & 131.9 & $\begin{array}{r}128.54 .7 \\
-10.5 \\
-0.8\end{array}$ & $\begin{array}{c}\text { 1-benzenne }: C^{\star} C^{\star} C^{\star} C^{\star} C^{\star} C^{\star} 1 \\
1-N-1: C^{\star} C^{\star} C^{\star} C^{\star} C^{\star} C^{\star} 1 \\
\text { general corrections }\end{array}$ \\
\hline c & 131.9 & $\begin{array}{r}128.10 .5 \\
14.7 \\
-0.8\end{array}$ & $\begin{array}{c}\text { 1-benzenne: } C^{\star} C^{\star} C^{\star} C^{\star} C^{\star} C^{\star} 1 \\
1-N-1: C^{\star} C^{\star} C^{\star} C^{\star} C^{\star} C^{\star} 1 \\
\text { general corrections }\end{array}$ \\
\hline c & 131.9 & $\begin{array}{r}128.54 .7 \\
-10.5 \\
-0.8\end{array}$ & $\begin{array}{l}\text { 1-benzenne: } C^{*} C^{\star} C^{\star} C^{*} C^{\star} C^{\star} 1 \\
1-N(C) C \\
\text { general corrections }\end{array}$ \\
\hline c & 130.8 & $\begin{array}{r}128.54 .7 \\
-11.6 \\
-0.8\end{array}$ & $\begin{array}{l}\text { 1-benzenne }: C^{\star} C^{\star} C^{\star} C^{\star} C^{\star} C^{\star} 1 \\
1-N-C \\
\text { general corrections }\end{array}$ \\
\hline c & 147.1 & $\begin{array}{r}128.50 .5 \\
16.0 \\
13.1\end{array}$ & $\begin{array}{l}\text { 1-benzenne }: C^{\star} C^{\star} C^{\star} C^{\star} C^{\star} C^{\star} 1 \\
1-N(C) C \\
\text { general corrections }\end{array}$ \\
\hline c & 139.5 & $\begin{array}{r}128.50 .5 \\
15.0 \\
6.5\end{array}$ & $\begin{array}{c}\text { 1-benzene }: C^{*} C^{*} C^{*} C^{*} C^{*} C^{*} 1 \\
1-N-C \\
\text { general corrections }\end{array}$ \\
\hline $\mathrm{CH}$ & 121.2 & $\begin{array}{r}128.50 .6 \\
0.9 \\
2.4\end{array}$ & $\begin{array}{c}\text { 1-benzegne : } C^{\star} C^{\star} C^{\star} C^{\star} C^{\star} C^{\star} 1 \\
1-N-1: C^{\star} C^{\star} C^{\star} C^{\star} C^{\star} C^{\star} 1 \\
\text { general corrections }\end{array}$ \\
\hline $\mathrm{CH}$ & 121.2 & $\begin{array}{r}128.50 .9 \\
-10.6 \\
2.4\end{array}$ & $\begin{array}{c}\text { 1-benzenne : } C^{\star} C^{\star} C^{\star} C^{\star} C^{\star} C^{\star} 1 \\
1-N-1: C^{\star} C^{\star} C^{\star} C^{\star} C^{\star} C^{\star} 1 \\
\text { general corrections }\end{array}$ \\
\hline $\mathrm{CH}$ & 121.2 & $\begin{array}{r}128=50.6 \\
0.9 \\
2.4\end{array}$ & $\begin{array}{c}\text { 1-benzenne: } C^{\star} C^{\star} C^{\star} C^{\star} C^{*} C^{\star} 1 \\
1-N(C) C \\
\text { general corrections }\end{array}$ \\
\hline $\mathrm{CH}$ & 121.1 & $\begin{array}{r}128.50 .6 \\
0.8 \\
2.4\end{array}$ & $\begin{array}{l}\text { 1-benzenne: } C^{*} C^{*} C^{\star} C^{*} C^{*} C^{\star} 1 \\
1-N-C \\
\text { general corrections }\end{array}$ \\
\hline $\mathrm{CH}$ & 113.7 & $\begin{array}{r}128.50 .9 \\
-15.4 \\
-0.3\end{array}$ & $\begin{array}{l}\text { 1-benzenne: } C^{\star} C^{\star} C^{\star} C^{\star} C^{\star} C^{\star} 1 \\
1-N(C) C \\
\text { general corrections }\end{array}$ \\
\hline $\mathrm{CH}$ & 118.6 & $\begin{array}{r}128.50 .9 \\
-16.2 \\
5.4\end{array}$ & $\begin{array}{c}\text { 1-benzene }: C^{*} C^{*} C^{*} C^{*} C^{*} C^{*} 1 \\
1-N-C \\
\text { general corrections }\end{array}$ \\
\hline $\mathrm{CH}$ & 121.2 & $\begin{array}{r}128.50 .6 \\
0.9 \\
2.4\end{array}$ & $\begin{array}{c}\text { 1-benzenne: } C^{\star} C^{\star} C^{\star} C^{\star} C^{\star} C^{\star} 1 \\
1-N-1: C^{\star} C^{\star} C^{\star} C^{\star} C^{\star} C^{\star} 1 \\
\text { general corrections }\end{array}$ \\
\hline $\mathrm{CH}$ & 121.2 & $\begin{array}{r}128.50 .9 \\
-10.6 \\
2.4\end{array}$ & $\begin{array}{c}\text { 1-benzenne: } C^{\star} C^{\star} C^{\star} C^{\star} C^{\star} C^{\star} 1 \\
1-N-1: C^{\star} C^{\star} C^{\star} C^{\star} C^{\star} C^{\star} 1 \\
\text { general corrections }\end{array}$ \\
\hline $\mathrm{CH}$ & 121.2 & $\begin{array}{r}128=50.6 \\
0.9 \\
2.4\end{array}$ & 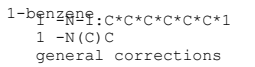 \\
\hline $\mathrm{CH}$ & 121.1 & 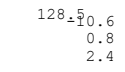 & $\begin{array}{l}\text { 1-benzegne }: C^{\star} C^{\star} C^{\star} C^{\star} C^{\star} C^{\star} 1 \\
1-N-C \\
\text { general corrections }\end{array}$ \\
\hline CH & 113.7 & $\begin{array}{r}128.50 .9 \\
-15.4 \\
-0.3\end{array}$ & $\begin{array}{c}\text { 1-benzenne: } C^{\star} C^{\star} C^{\star} C^{\star} C^{\star} C^{\star} 1 \\
1-N(C) C \\
\text { general corrections }\end{array}$ \\
\hline $\mathrm{CH}$ & 118.6 & $\begin{array}{r}128.50 .9 \\
-16.2 \\
5.4\end{array}$ & $\begin{array}{l}\text { 1-benzegne }: C^{\star} C^{\star} C^{\star} C^{\star} C^{\star} C^{\star} 1 \\
1-N-C \\
\text { general corrections }\end{array}$ \\
\hline $\mathrm{CH} 3$ & 41.3 & $\begin{array}{r}-2.38 .3 \\
9.3 \\
9.4 \\
-3.4\end{array}$ & $\begin{array}{l}\text { aliphatatipa }-\mathrm{N} \\
1 \text { beta }-1: \mathrm{C}^{\star} \mathrm{C}^{\star} \mathrm{C}^{\star} \mathrm{C}^{\star} \mathrm{C}^{\star} \mathrm{C}^{\star} 1 \\
1 \text { beta }-\mathrm{C} \\
\text { general corrections }\end{array}$ \\
\hline CH3 & 41.3 & $\begin{array}{r}-2 . \underline{3} 8.3 \\
9.3 \\
9.4 \\
-3.4\end{array}$ & $\begin{array}{l}\text { aliphatetifia }-\mathrm{N} \\
1 \text { beta }-1: \mathrm{C}^{\star} \mathrm{C}^{\star} \mathrm{C}^{\star} \mathrm{C}^{\star} \mathrm{C}^{\star} \mathrm{C}^{\star} 1 \\
1 \text { beta - } \mathrm{C} \\
\text { general corrections }\end{array}$ \\
\hline $\mathrm{CH} 3$ & 29.6 & $\begin{array}{r}-2.38 .3 \\
9.3 \\
-5.7\end{array}$ & $\begin{array}{l}\text { aliphatiojfia -N } \\
\quad 1 \text { beta }-1: C^{\star} C^{\star} C^{\star} C^{\star} C^{\star} C^{\star} 1 \\
\text { general corrections }\end{array}$ \\
\hline
\end{tabular}

Figure S10 Calculation results of the ChemNMR ${ }^{13} \mathrm{C}$ for the CMPA-3 by ChemDraw Professional 17.0 . 
S2.1.7 Amorphous CMPA networks confirmed by PXRD study.

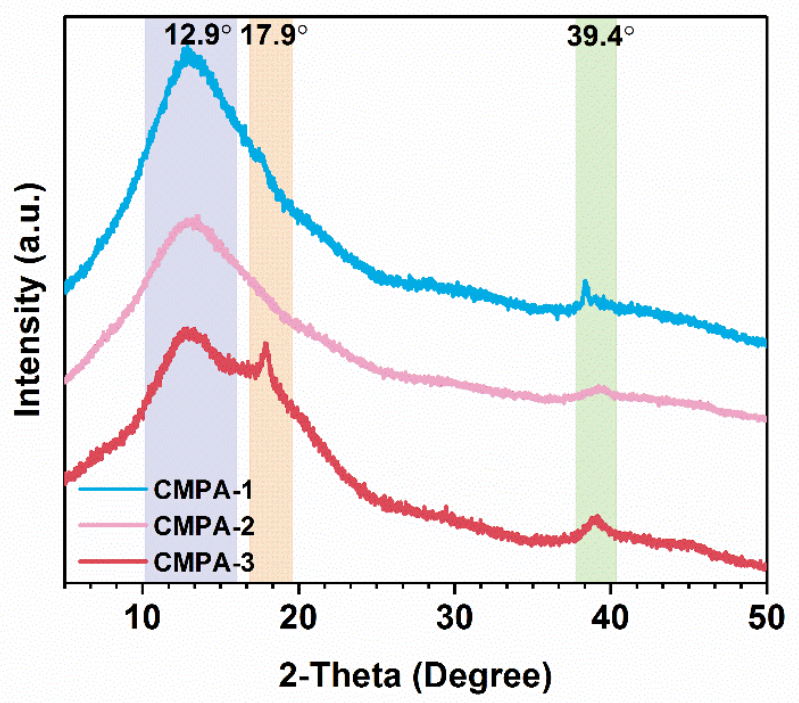

Figure S11 Powder XRD patterns of the CMPA networks. 
S2.1.8 Element analysis by TEM mapping study.

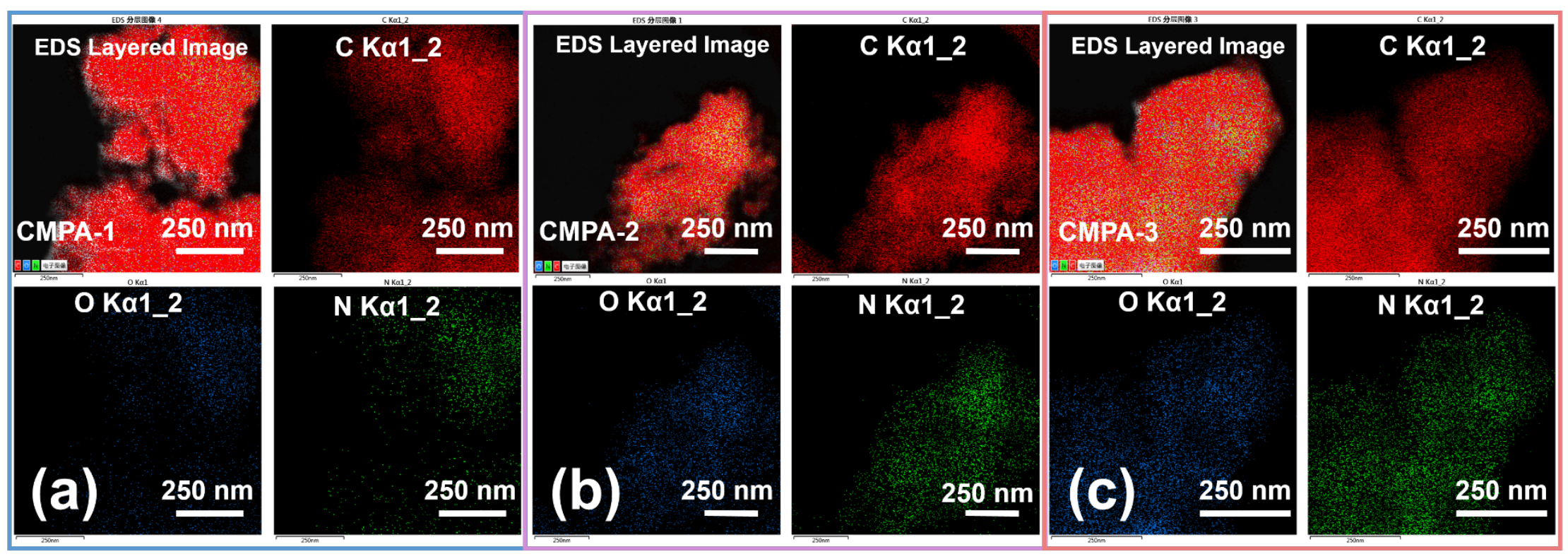

Figure S12 TEM mapping images of the CMPA networks (CMPA-1, a; CMPA-2, b; CMPA-3, c). 


\section{S2.2. Batch adsorption experiment}

\section{S2.2.1 Optimization}
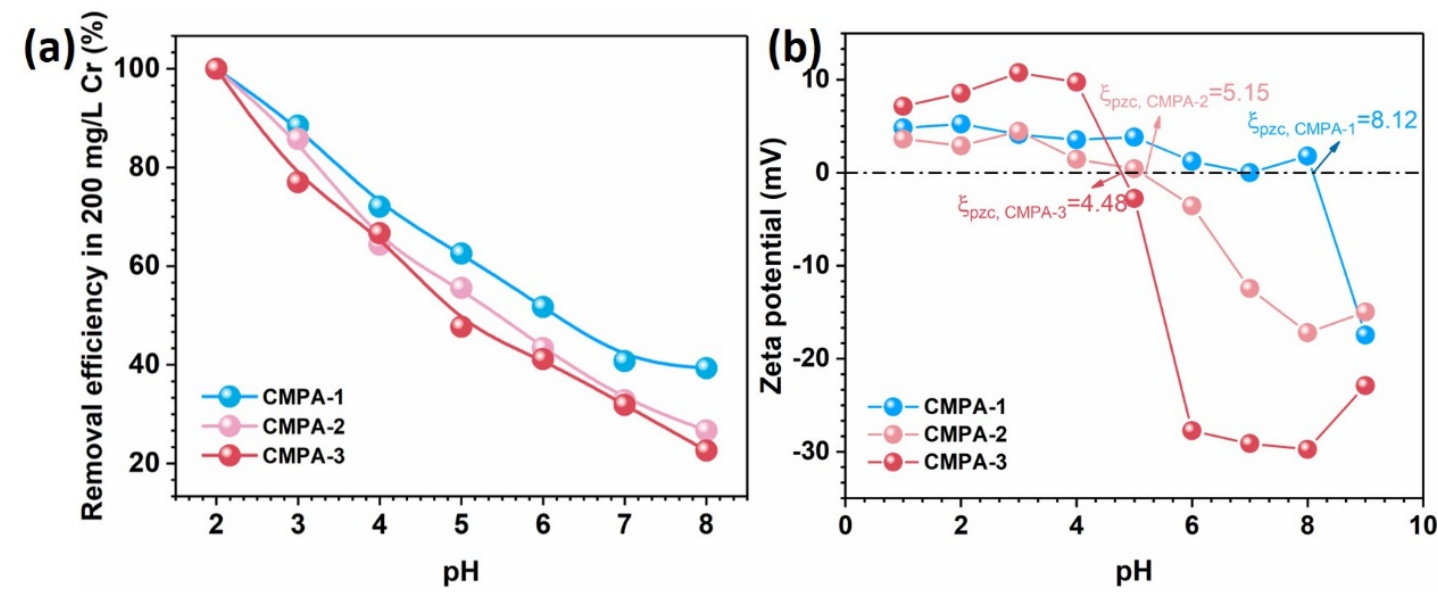

Figure S13 (a) Removal efficiency of CMPA networks for $\mathrm{Cr}(\mathrm{VI})$ in the solution with different $\mathrm{pH}$; (b) zeta potentials on CMPA networks in the solution with different $\mathrm{pH}$. 


\section{S2.2.2 Kinetics}
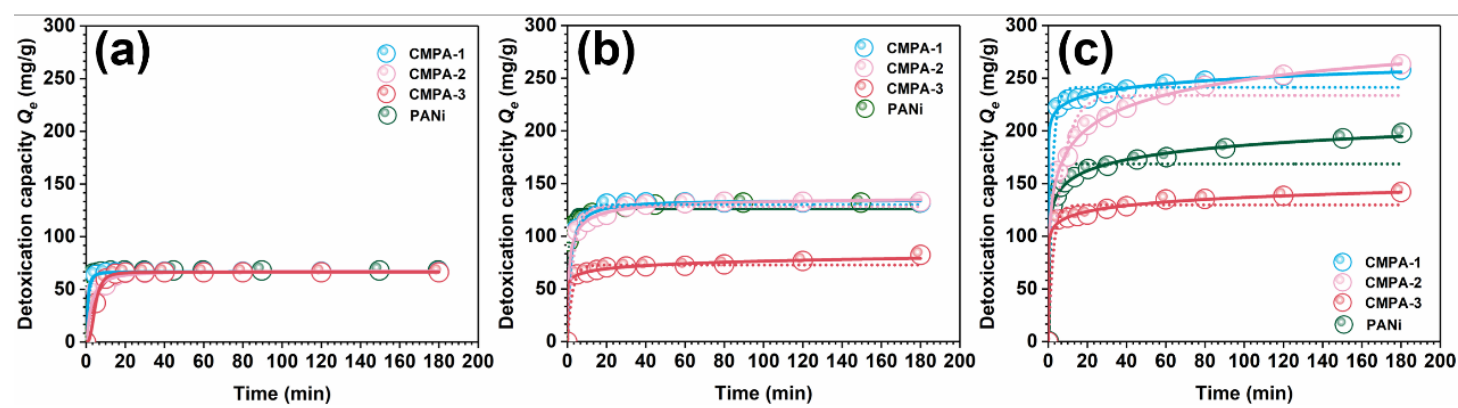

Figure S14 Adsorption kinetics of CMPA networks compared to PANI towards $\mathrm{Cr}(\mathrm{VI})$ under initial concentration of $100 \mathrm{mg} / \mathrm{L} \mathrm{(a),} 200 \mathrm{mg} / \mathrm{L}$ (b) and $400 \mathrm{mg} / \mathrm{L}$ (c) of Cr(VI). 


\section{S2.2.3 Isotherm}

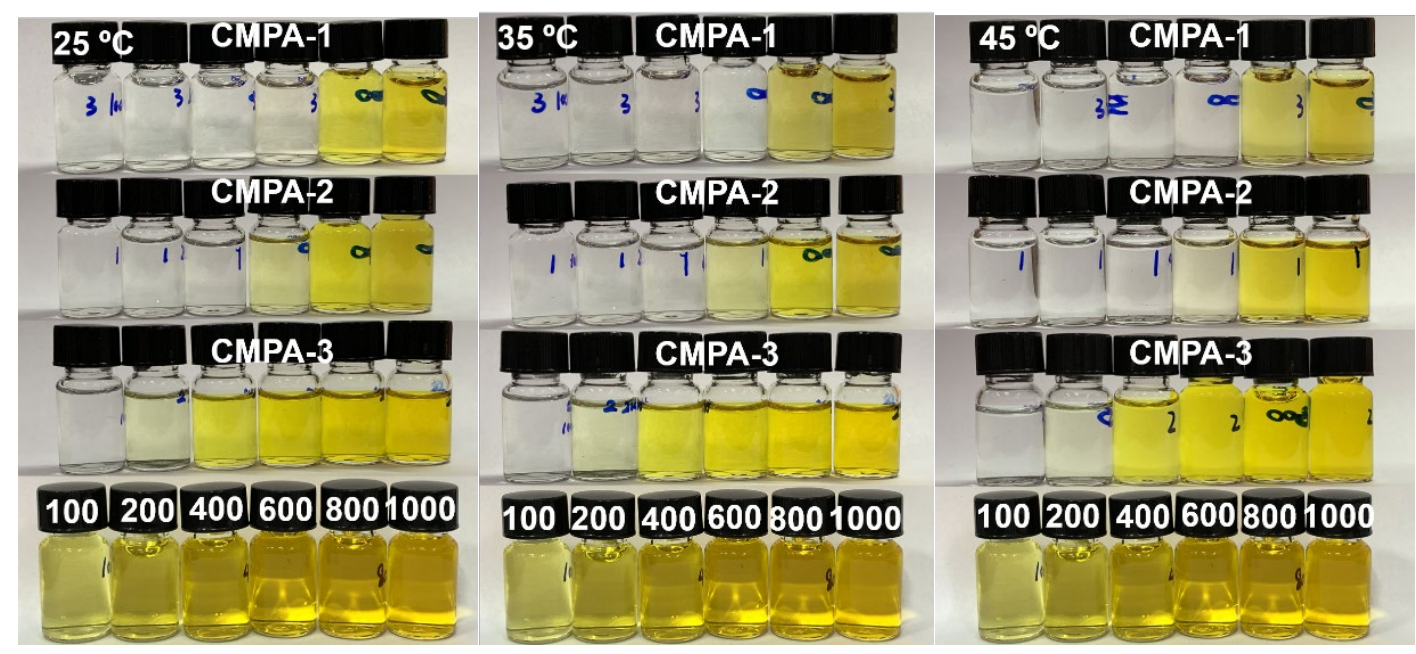

Figure S15 Photos of Cr(VI) solution with various initial concentrations after adsorption by CMPA networks under $25^{\circ} \mathrm{C}$ (a), $35^{\circ} \mathrm{C}(\mathrm{b})$ and $45^{\circ} \mathrm{C}$ (c).
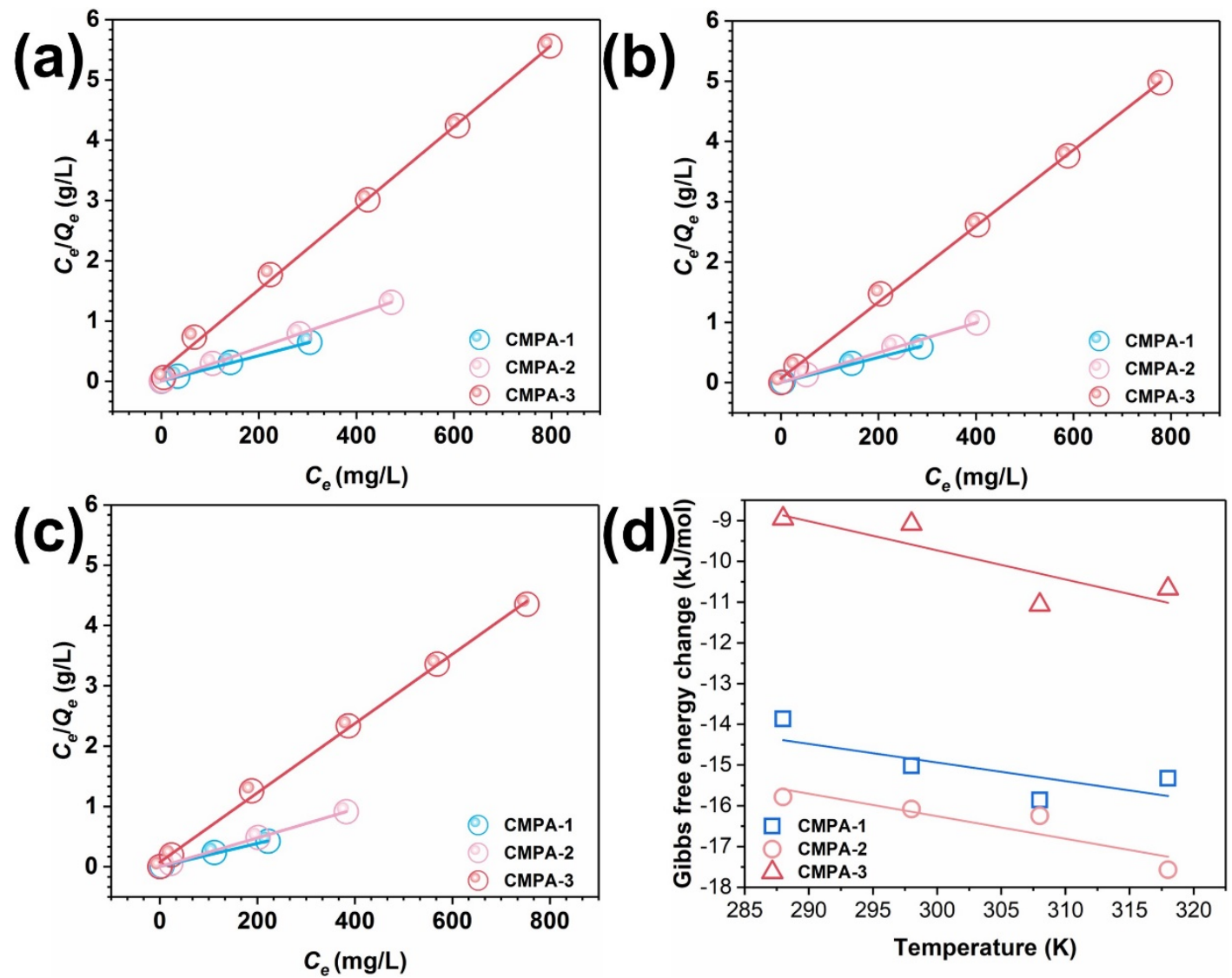

Figure S16 Linear adsorption isotherm fitted by Langmuir model of CMPA networks towards Cr(VI) under $298 \mathrm{~K}(\mathrm{a}), 308 \mathrm{~K}$ (b), $318 \mathrm{~K}$ (c); thermodynamic parameter calculation through the vant Hoff equation with the isothermal data obtained in $288 \mathrm{~K}, 298 \mathrm{~K}, 308 \mathrm{~K}$ and $318 \mathrm{~K}$ (d). 

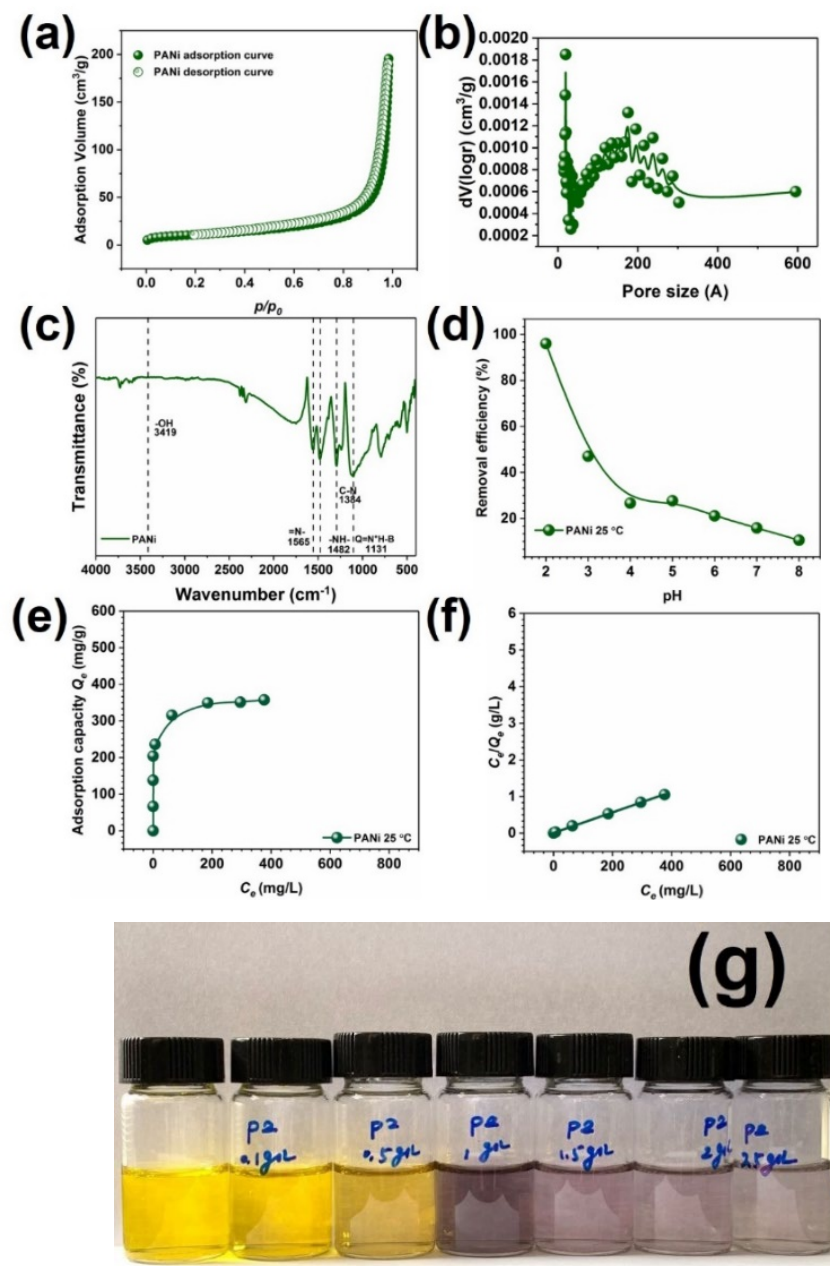

Figure S17 $\mathrm{N}_{2}$ adsorption and desorption isotherm (a), BJH pore size distribution (b), FTIR spectra (c) of the counter-part of CMPA networks- polyaniline and its adsorption capacities in different $\mathrm{pH}$ solution (initial concentration of $200 \mathrm{mg} / \mathrm{L}$ of $\mathrm{Cr}(\mathrm{VI})$, d), in different initial concentration of $\mathrm{Cr}(\mathrm{VI})$ (e) and its linear adsorption isotherm fitted by Langmuir model (f) and the photo of Cr solution after treated by polyaniline (PANI) with different dosage (initial concentration of $\mathrm{Cr}(\mathrm{VI})$ is $200 \mathrm{mg} / \mathrm{L}$ ). 

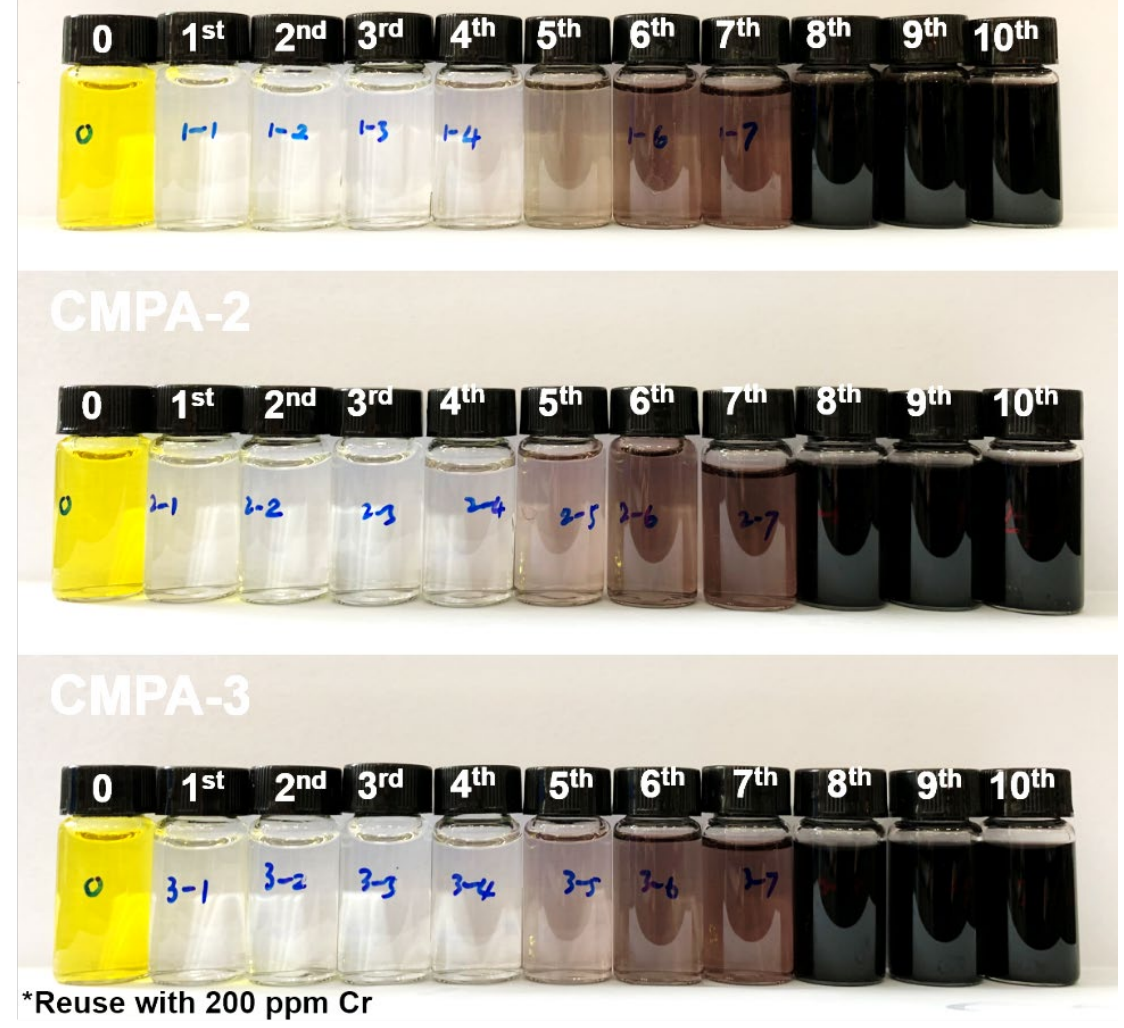

Figure S18 Photos of Cr(VI) solution in every repeating use after detoxication by CMPA networks. 


\section{S2.2.5 Adsorption mechanism}

(1) Properties of CMPA networks changed by $\mathrm{Cr}$ (VI)

1) Thermo-stability
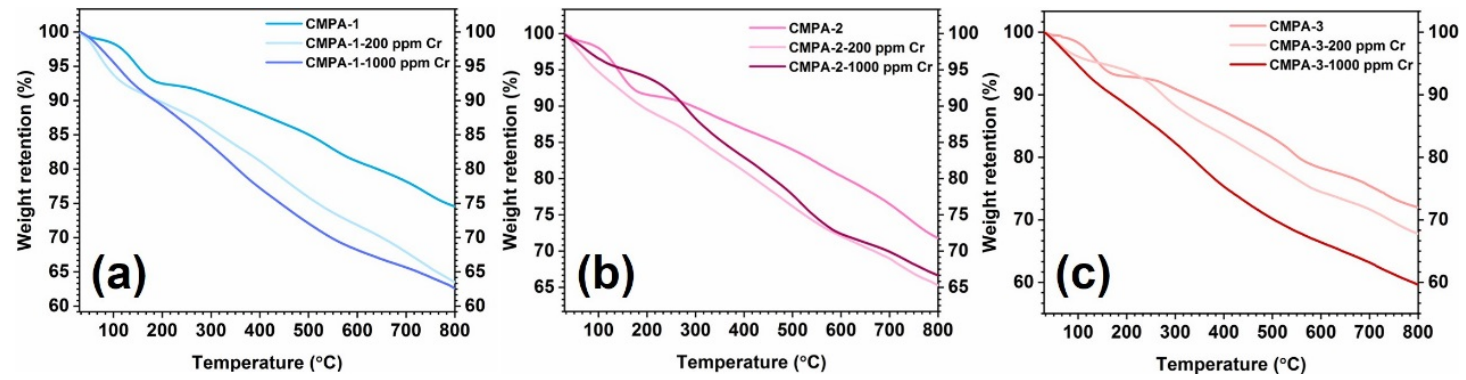

Figure S19 TGA curve of the CMPA networks after adsorption (CMPA-1, a; CMPA-2, b; CMPA-

$3, c)$.
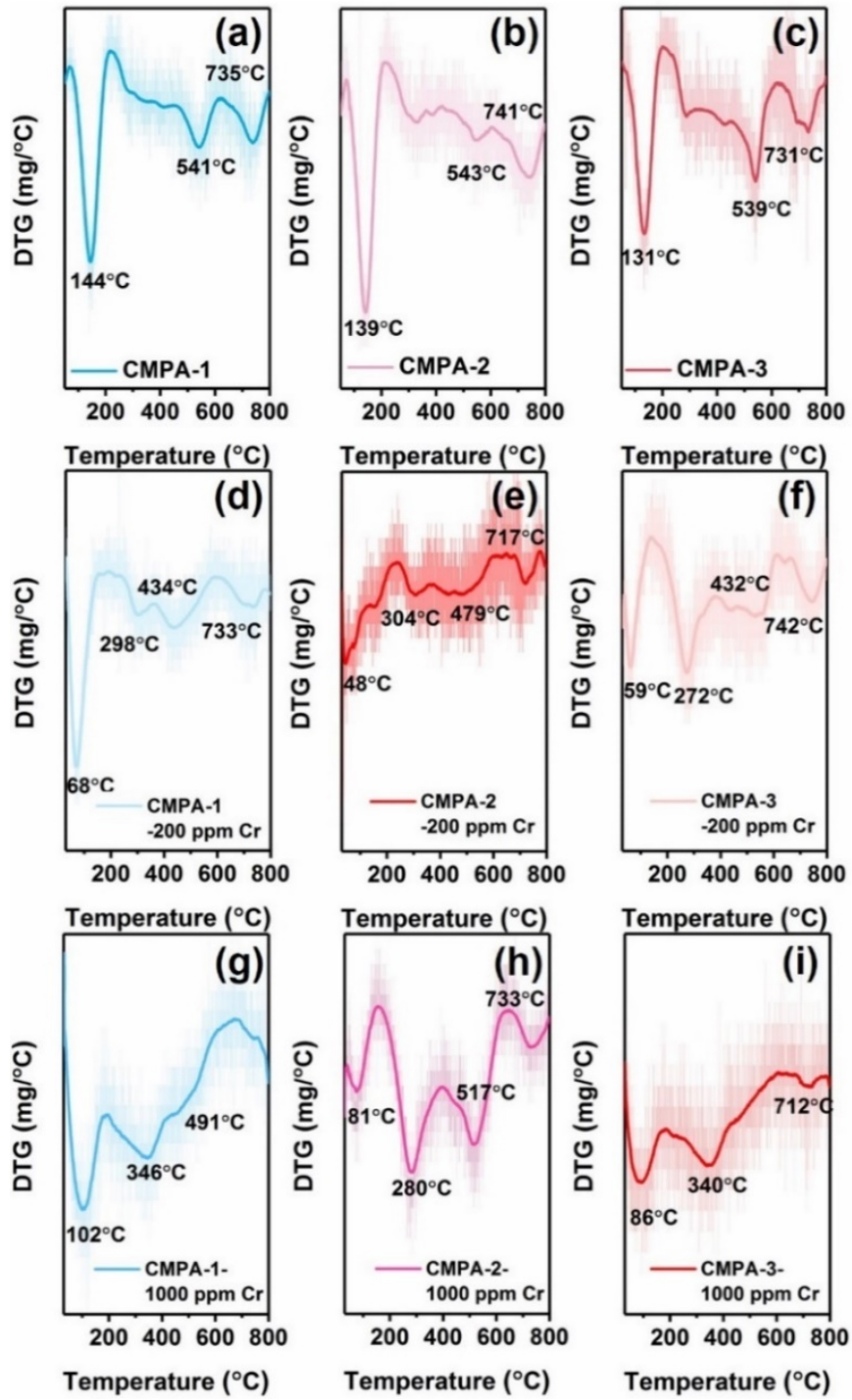

Figure S20 DTG curve of the CMPA networks before (CMPA-1, a; CMPA-2, b; CMPA-3, c) and after (CMPA-1 with $200 \mathrm{mg} / \mathrm{L}$ (d) and $1000 \mathrm{mg} / \mathrm{L}$ (g); CMPA-2 with $200 \mathrm{mg} / \mathrm{L}$ (e) and $1000 \mathrm{mg} / \mathrm{L}$ (h); CMPA-3 with $200 \mathrm{mg} / \mathrm{L}$ (f) and $1000 \mathrm{mg} / \mathrm{L}$ (i)). 
2) SEM images after adsorption

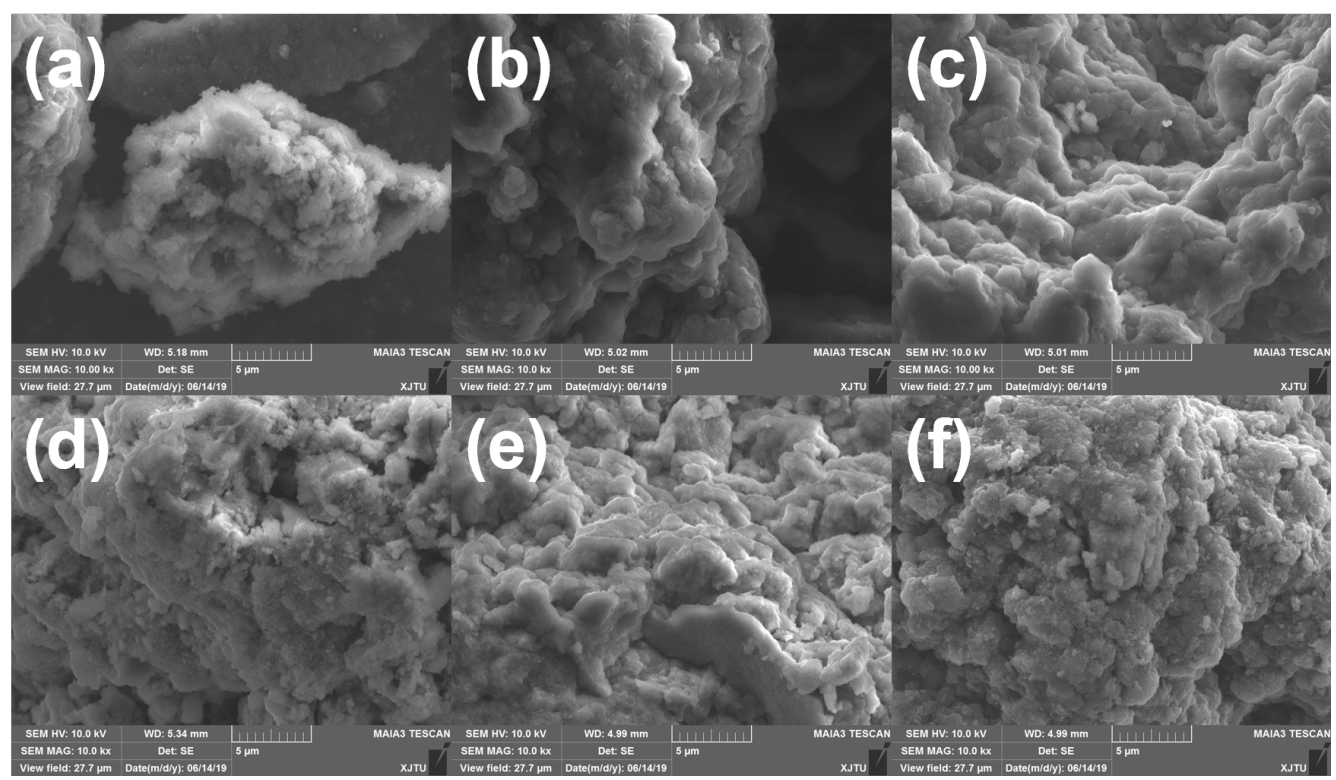

Figure S21 SEM images of the CMPA networks before (CMPA-1, a; CMPA-2, b; CMPA-3, c) and after (CMPA-1, d; CMPA-2, e; CMPA-3, f) interaction with $600 \mathrm{mg} / \mathrm{L} \mathrm{Cr}(\mathrm{VI})$. 
3) TEM-mapping image
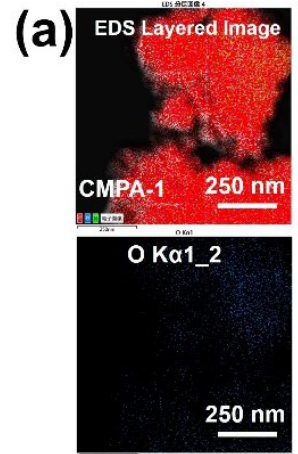
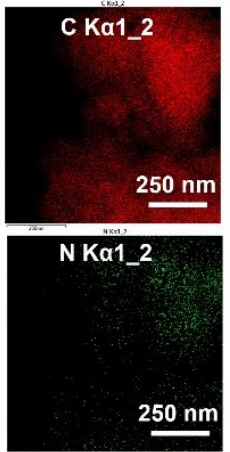

(b) EDS Layered Image

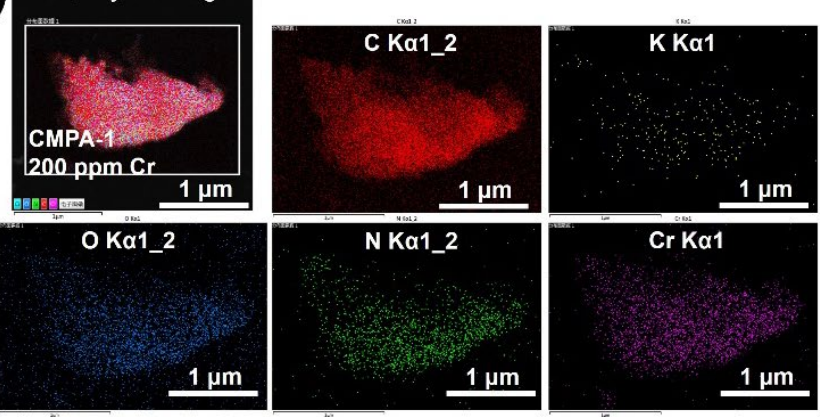

Figure S22 TEM-mapping images of the CMPA-1 networks before (a) and after interaction with $200 \mathrm{mg} / \mathrm{L}$ Cr(VI) (b).

(a)
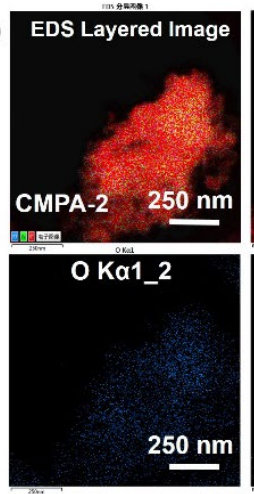

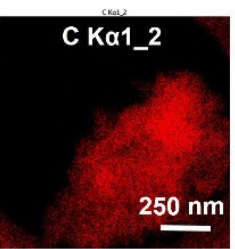

N Ka1_2

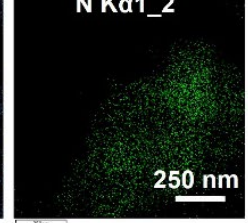

(b)

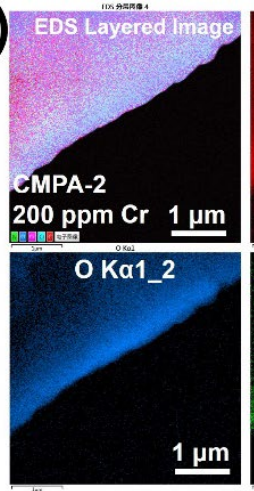

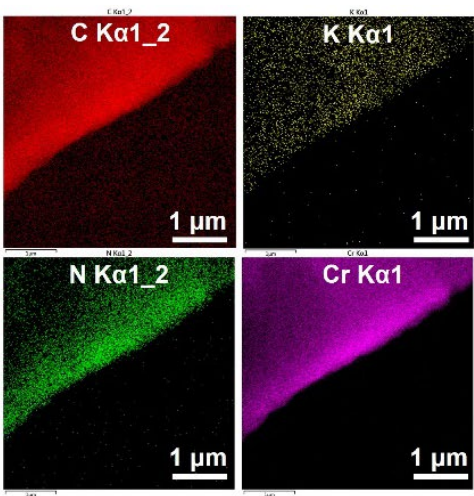

Figure S23 TEM-mapping images of the CMPA-2 networks before (a) and after interaction with $200 \mathrm{mg} / \mathrm{L} \mathrm{Cr}(\mathrm{VI})(\mathrm{b})$.

(a)

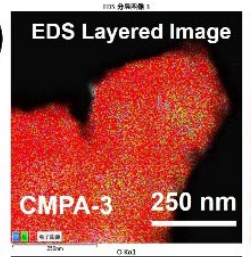

0 Ka1_2
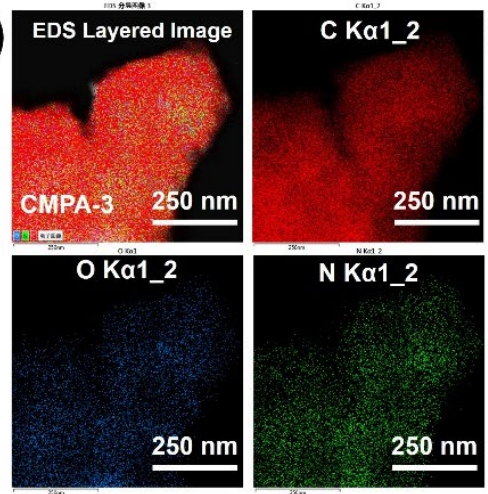
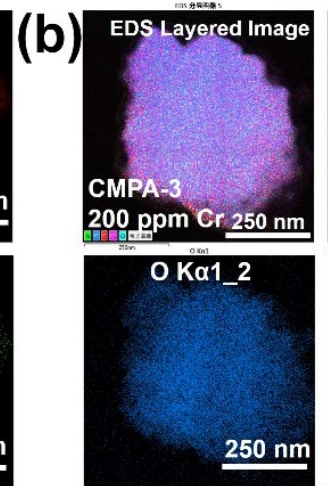
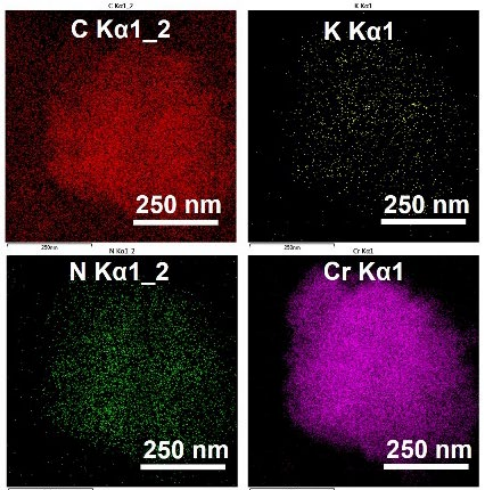

Figure S24 TEM-mapping images of the CMPA-3 networks before (a) and after interaction with $200 \mathrm{mg} / \mathrm{L} \mathrm{Cr}(\mathrm{VI})(\mathrm{b})$. 
(2) Verification for selectivity mechanism of the molecular-size-recognition.

1) TEM images

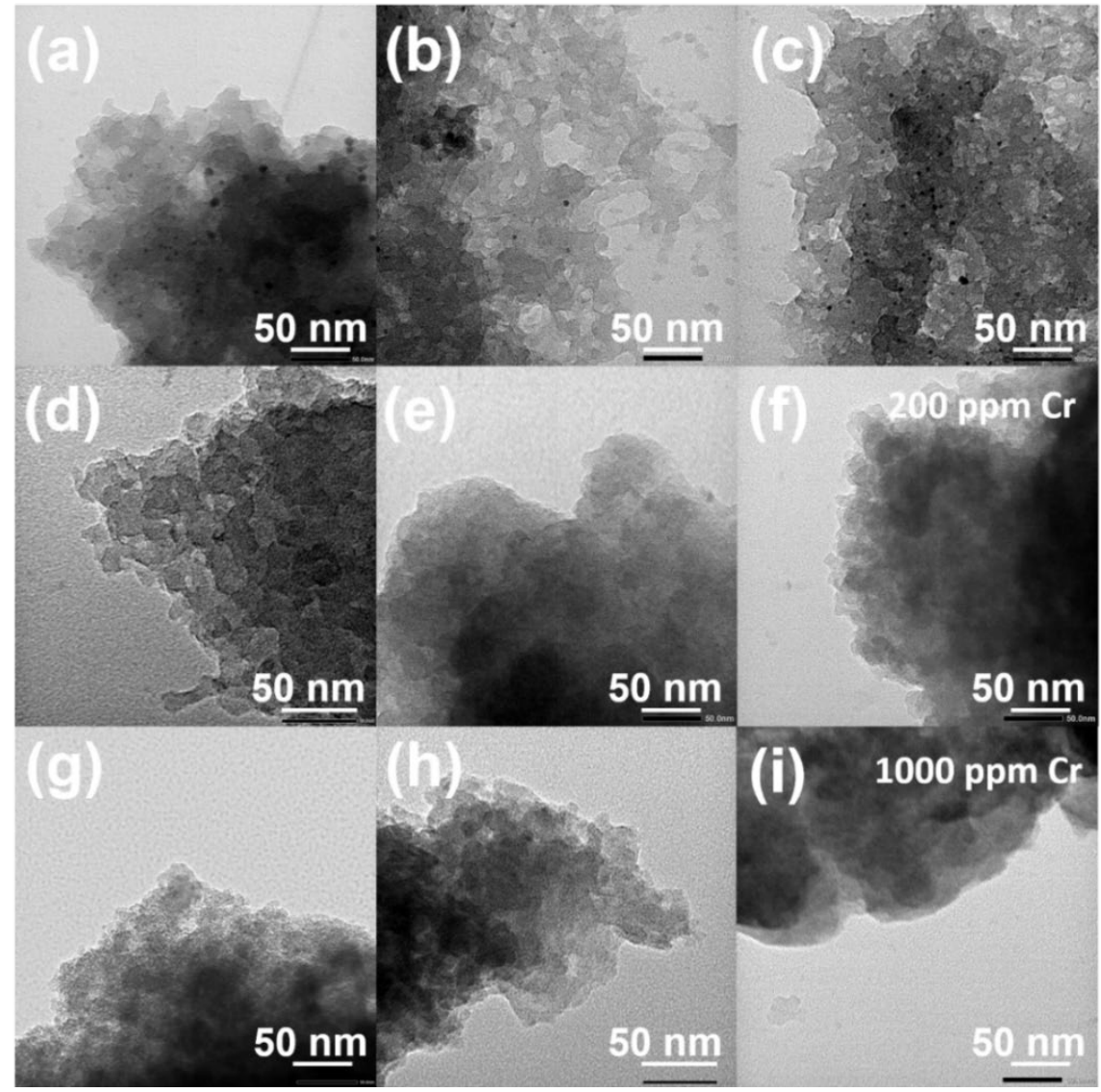

Figure S25 TEM images of CMPA networks before (CMPA-1, a; CMPA-2, b; CMPA-3, c) and after 200 mg/L (CMPA-1, d; CMPA-2, e; CMPA-3, f) or 1000 mg/L (CMPA-1, g; CMPA-2, h; CMPA-3, i) of $\mathrm{Cr}(\mathrm{VI})$ detoxication at low resolution (scale bar of $50 \mathrm{~nm}$ ). 


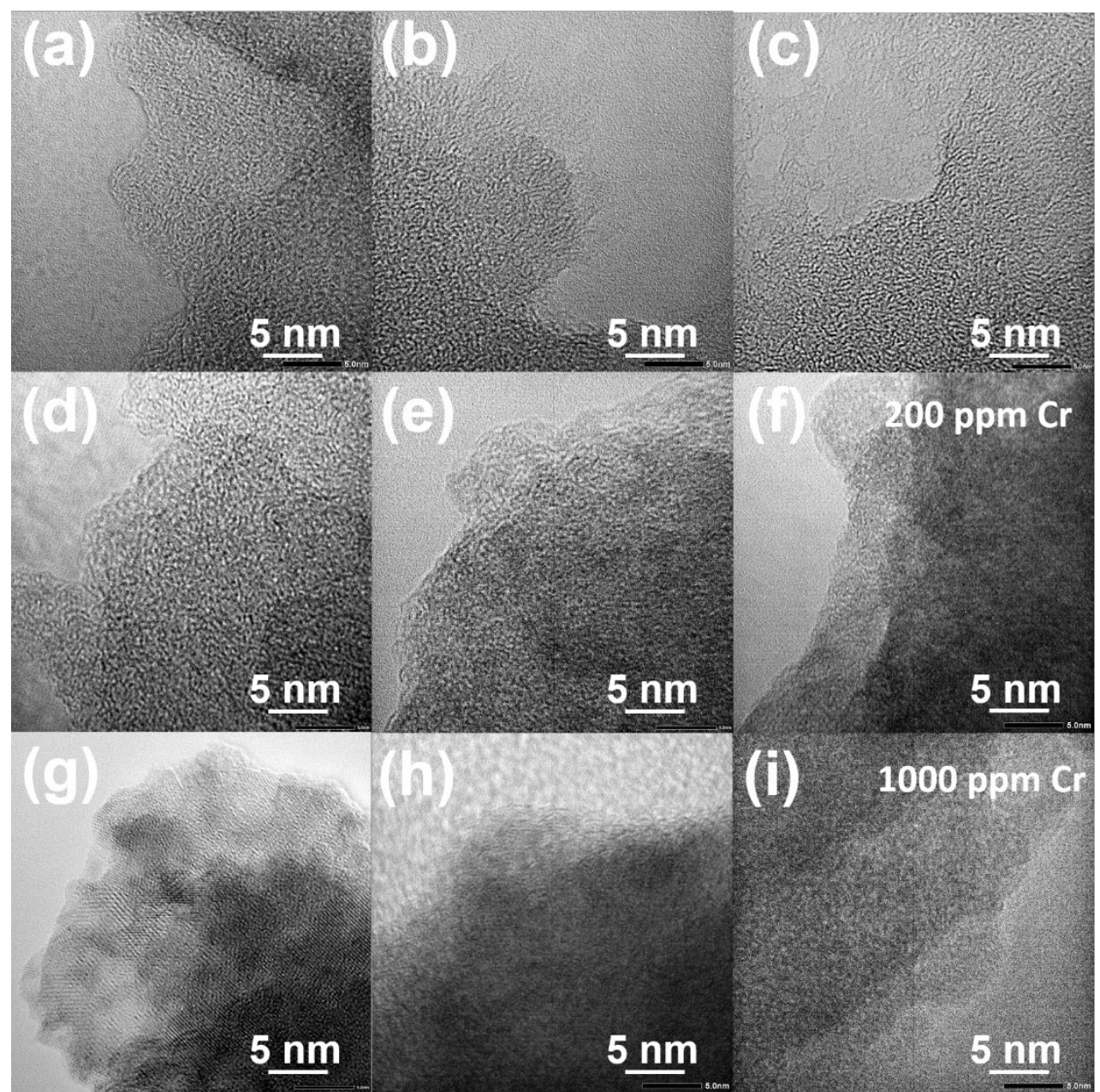

Figure S26 TEM images of CMPA networks before (CMPA-1, a; CMPA-2, b; CMPA-3, c) and after 200 mg/L (CMPA-1, d; CMPA-2, e; CMPA-3, f) or 1000 mg/L (CMPA-1, g; CMPA-2, h; CMPA-3, i) $\mathrm{Cr}(\mathrm{VI})$ detoxication at high resolution (scale bar of $5 \mathrm{~nm}$ ). 
2) $\mathrm{N}_{2}$ adsorption and desorption isotherm
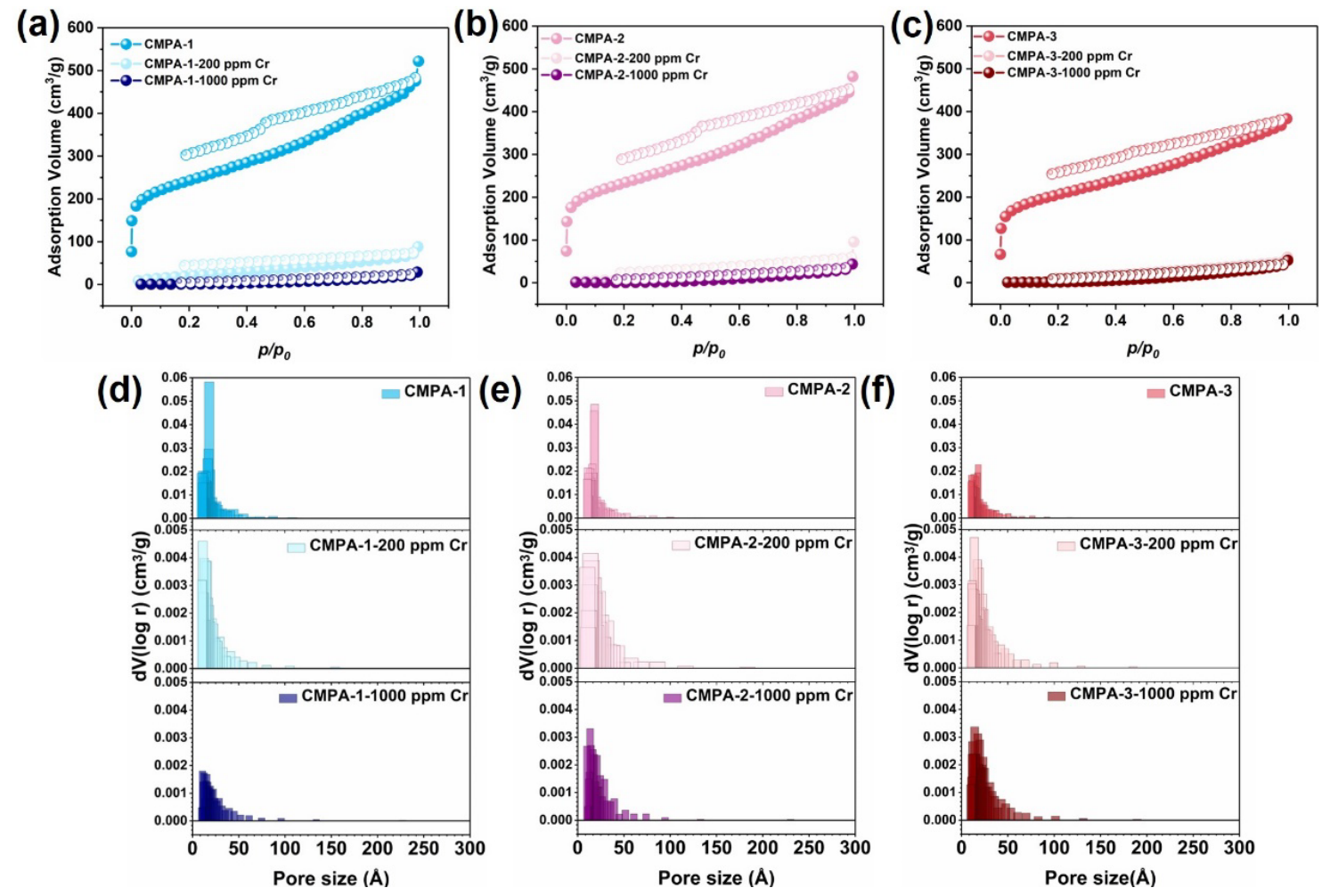

Figure $\mathbf{S 2 7} \mathrm{N}_{2}$ adsorption and desorption isotherm (CMPA-1, a; CMPA-2, b; CMPA-3, c) and BJH pore size distribution of the CMPA networks before and after $\mathrm{Cr}(\mathrm{VI})$ detoxication (CMPA-1, d; CMPA-2, e; CMPA-3, f). 
(3) Adsorption mechanism for Cr(VI) of CMPA networks.

1) FTIR

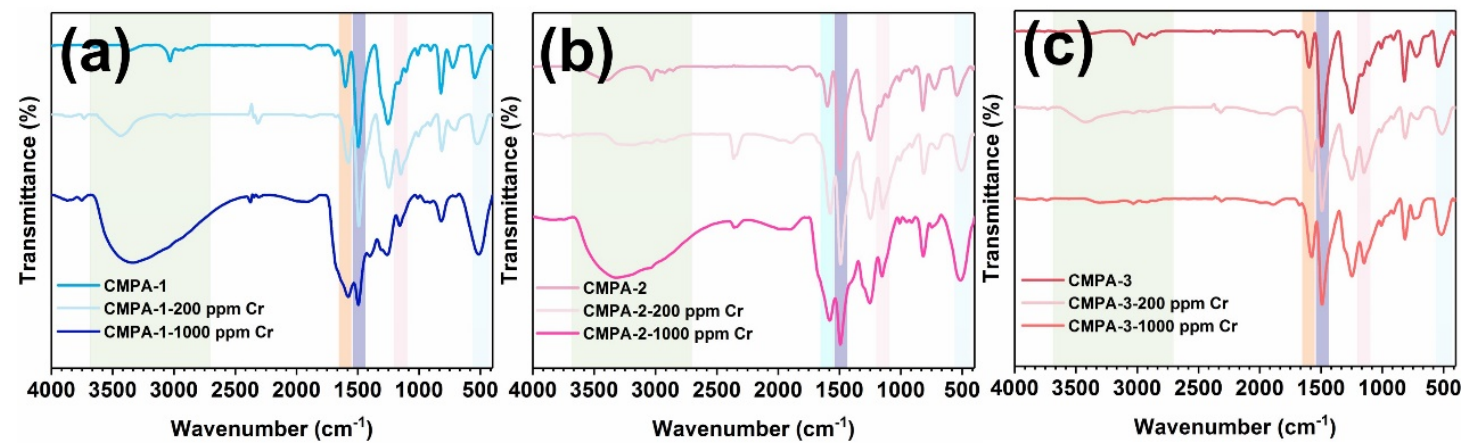

Figure S28 FTIR spectra of the CMPA networks after adsorption. 
2) $X P S$
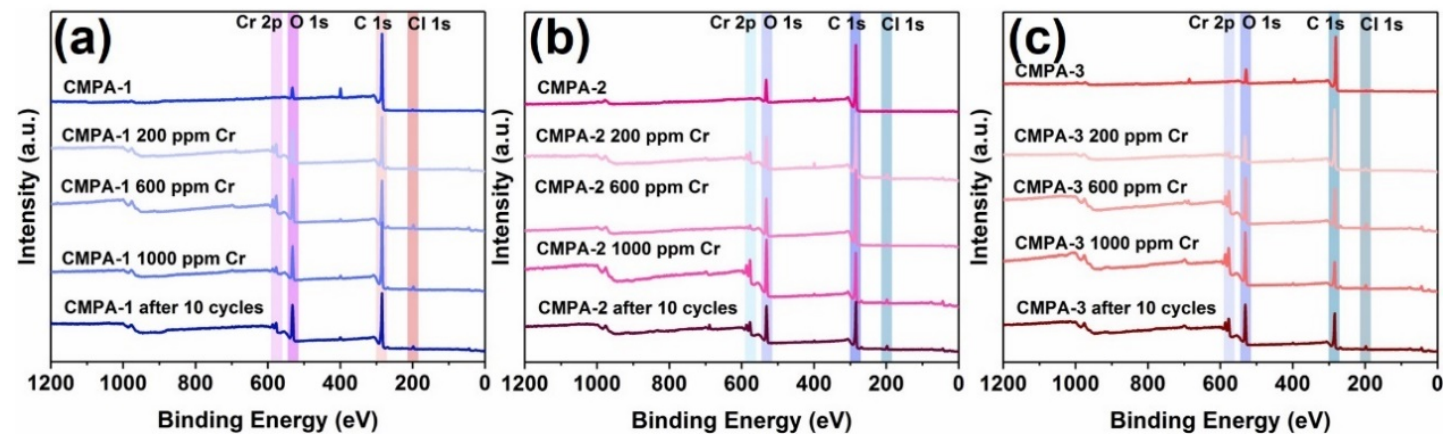

Figure S29 Full scale of XPS spectra of the CMPA networks after adsorption.

(a)

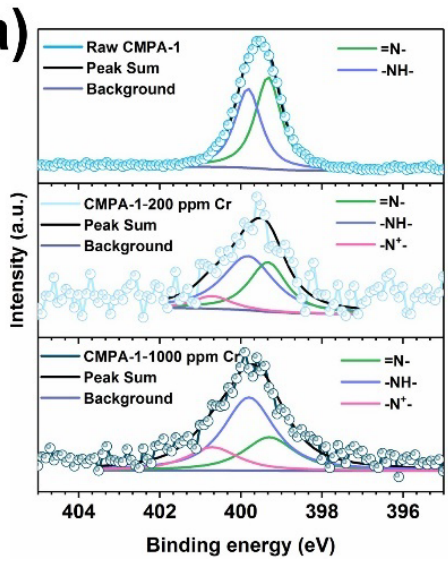

(b)

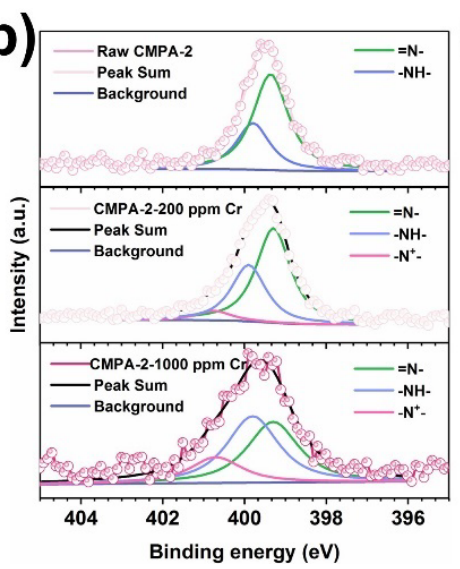

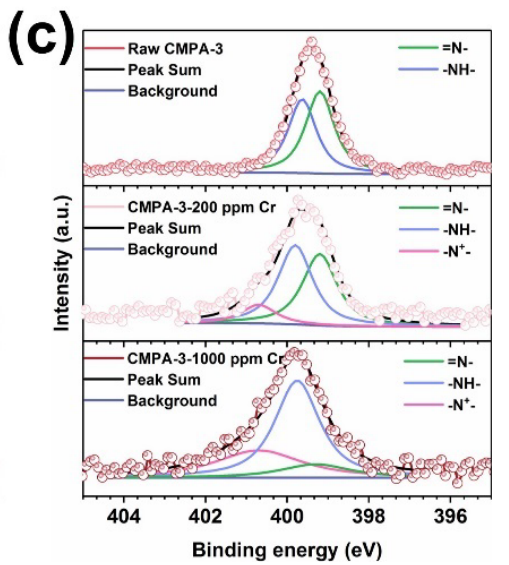

Figure S30 N 1s XPS spectra of the CMPA networks after interaction with various concentration of Cr(VI) (CMPA-1, a; CMPA-2, b; CMPA-3, c).

(a)

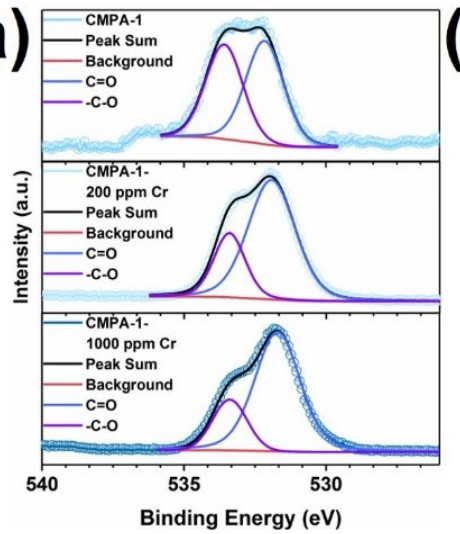

(b)

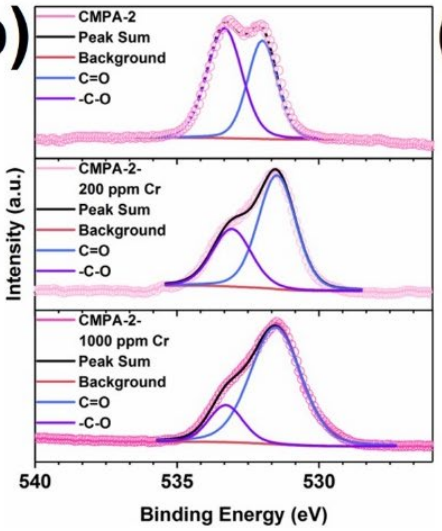

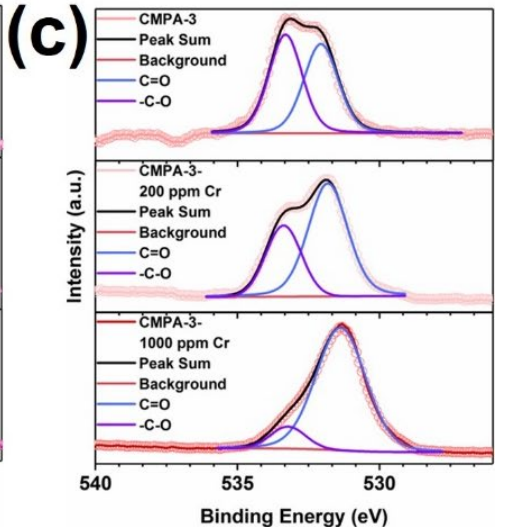

Figure S31 O 1s XPS spectra of the CMPA networks after interaction with various concentration of Cr(VI) (CMPA-1, a; CMPA-2, b; CMPA-3, c). 

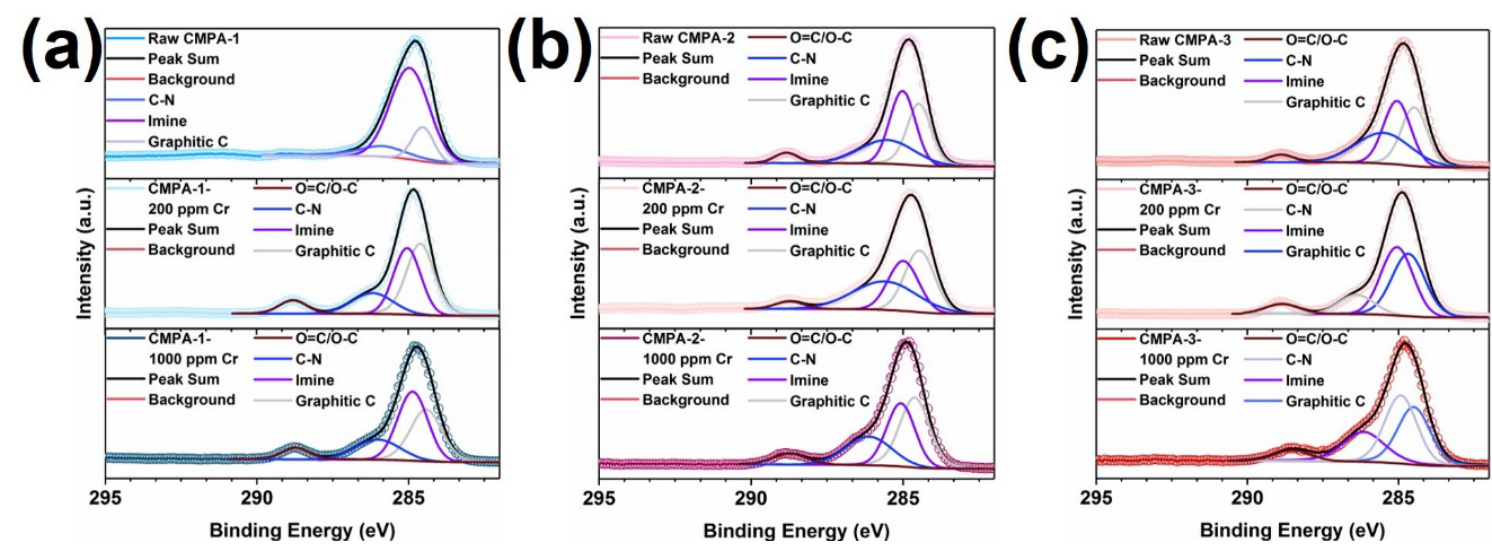

Figure S32 C 1s XPS spectra of the CMPA networks after interaction with various concentration of Cr(VI) (CMPA-1, a; CMPA-2, b; CMPA-3, c). 


\section{S2.2.6 Self-reduction mechanism}

(1) Properties of CMPA networks changed by $\mathrm{Cr}$ (VI) after 10 cycles.

1) $X P S$
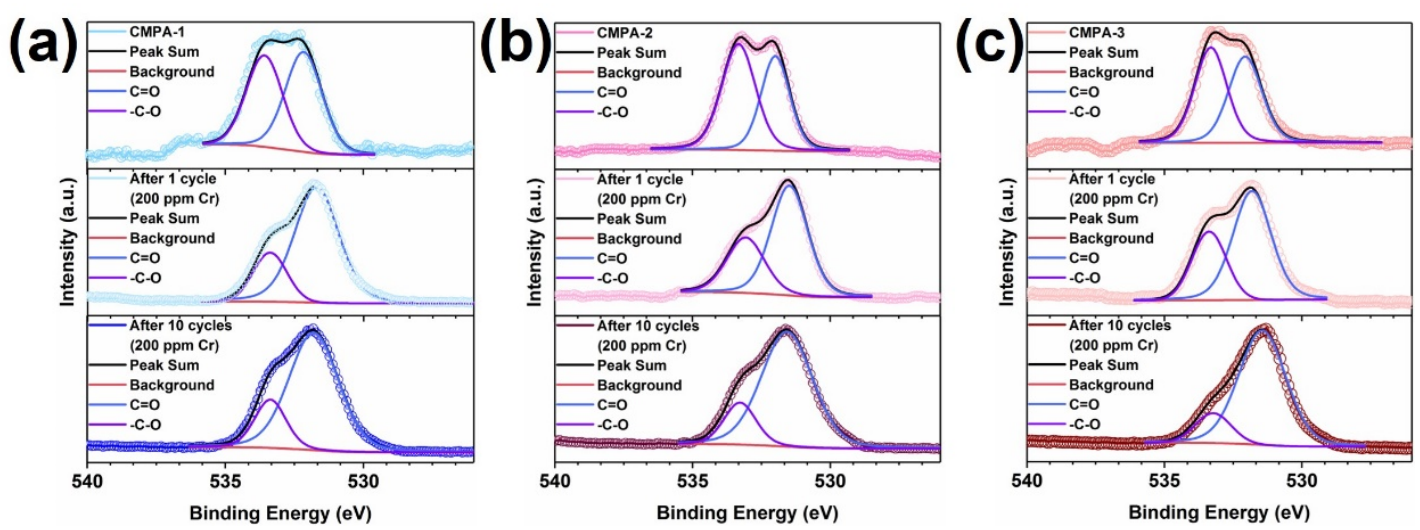

Figure S33 O 1s XPS spectra of the CMPA networks after 1 cycle and 10 cycles detoxication of $\mathrm{Cr}(\mathrm{VI})(200 \mathrm{mg} / \mathrm{L})$. 


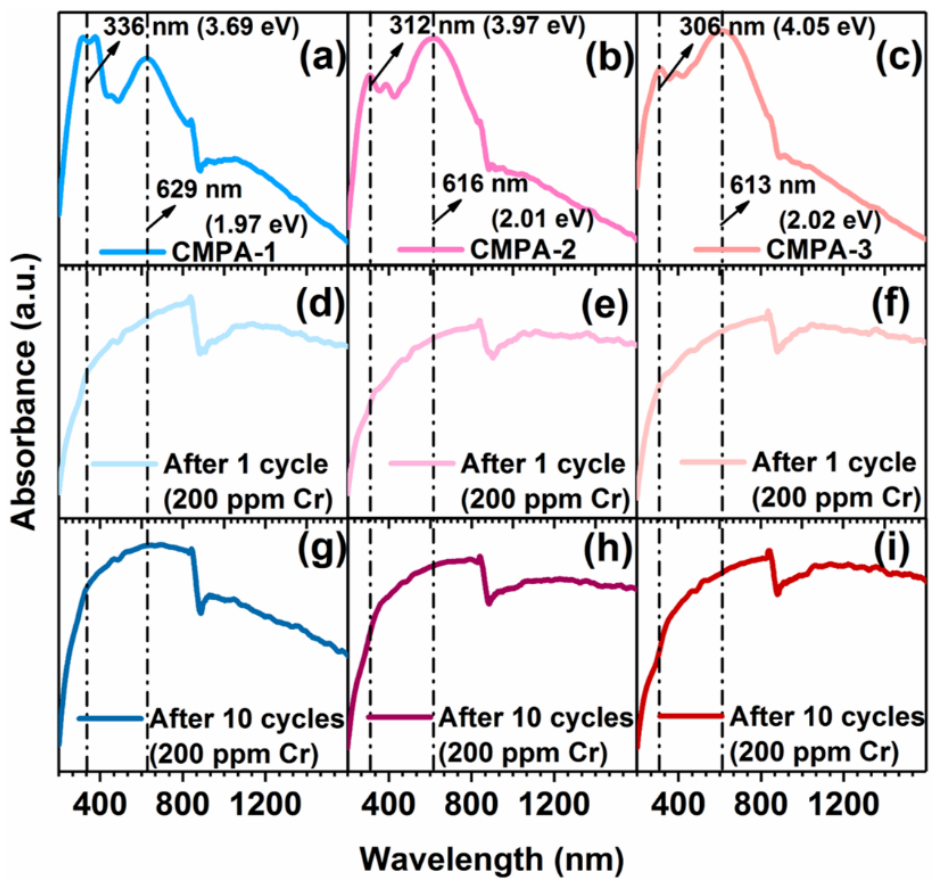

Figure S34 Solid-state UV/Vis diffuse-reflectance spectra of the CMPA networks after 1 cycle and 10 cycles detoxication of $\mathrm{Cr}(\mathrm{VI})(200 \mathrm{mg} / \mathrm{L})$. 
3) Thermo-stability
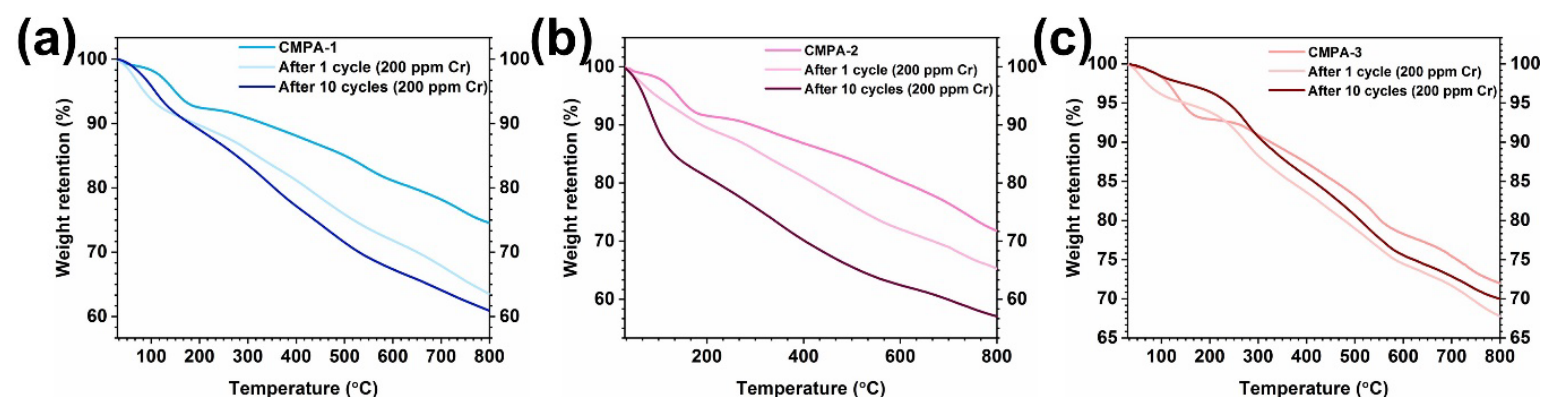

Figure S35 TGA curve of the CMPA networks after cycling detoxication (CMPA-1, a; CMPA-2, b; CMPA-3, c).
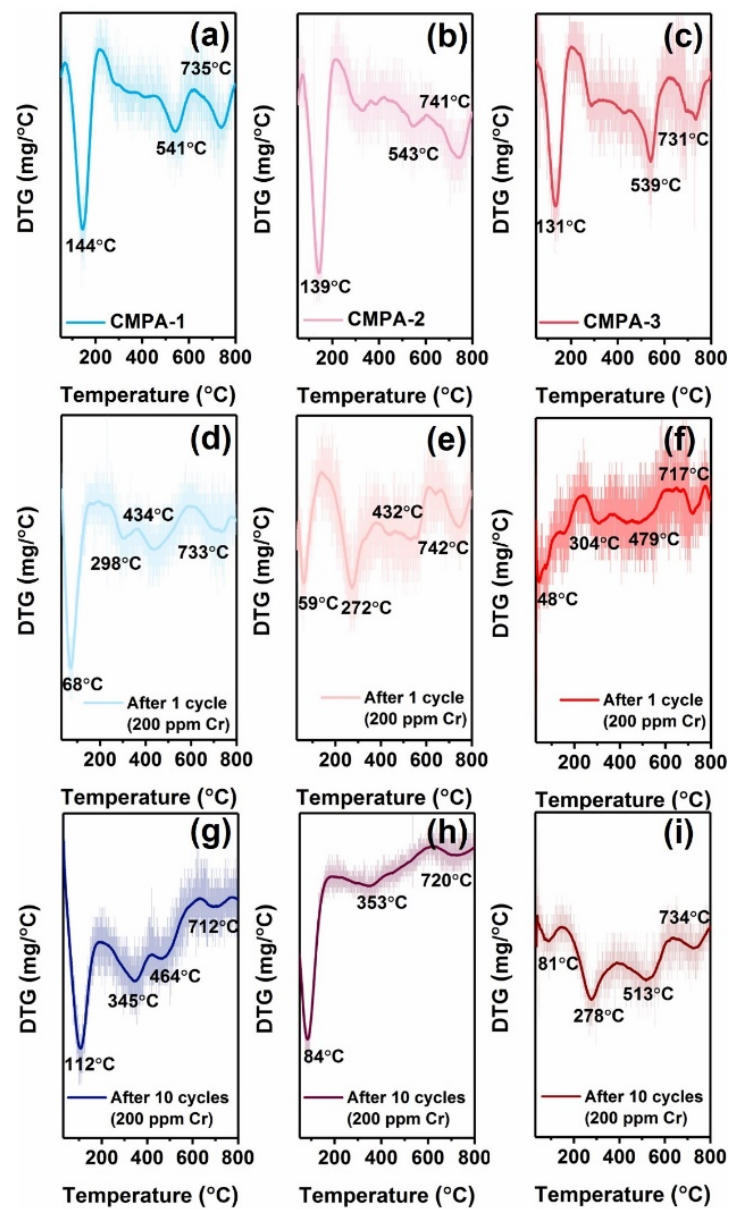

Figure S36 DTG curve of the CMPA networks before (CMPA-1, a; CMPA-2, b; CMPA-3, c) and after 1 cycle (CMPA-1, d; CMPA-2, e; CMPA-3, f) and 10 cycles (CMPA-1, g; CMPA-2, h; CMPA3 , i) of $\mathrm{Cr}(\mathrm{VI})$ detoxication. 
4) $\mathrm{N}_{2}$ adsorption and desorption isotherm
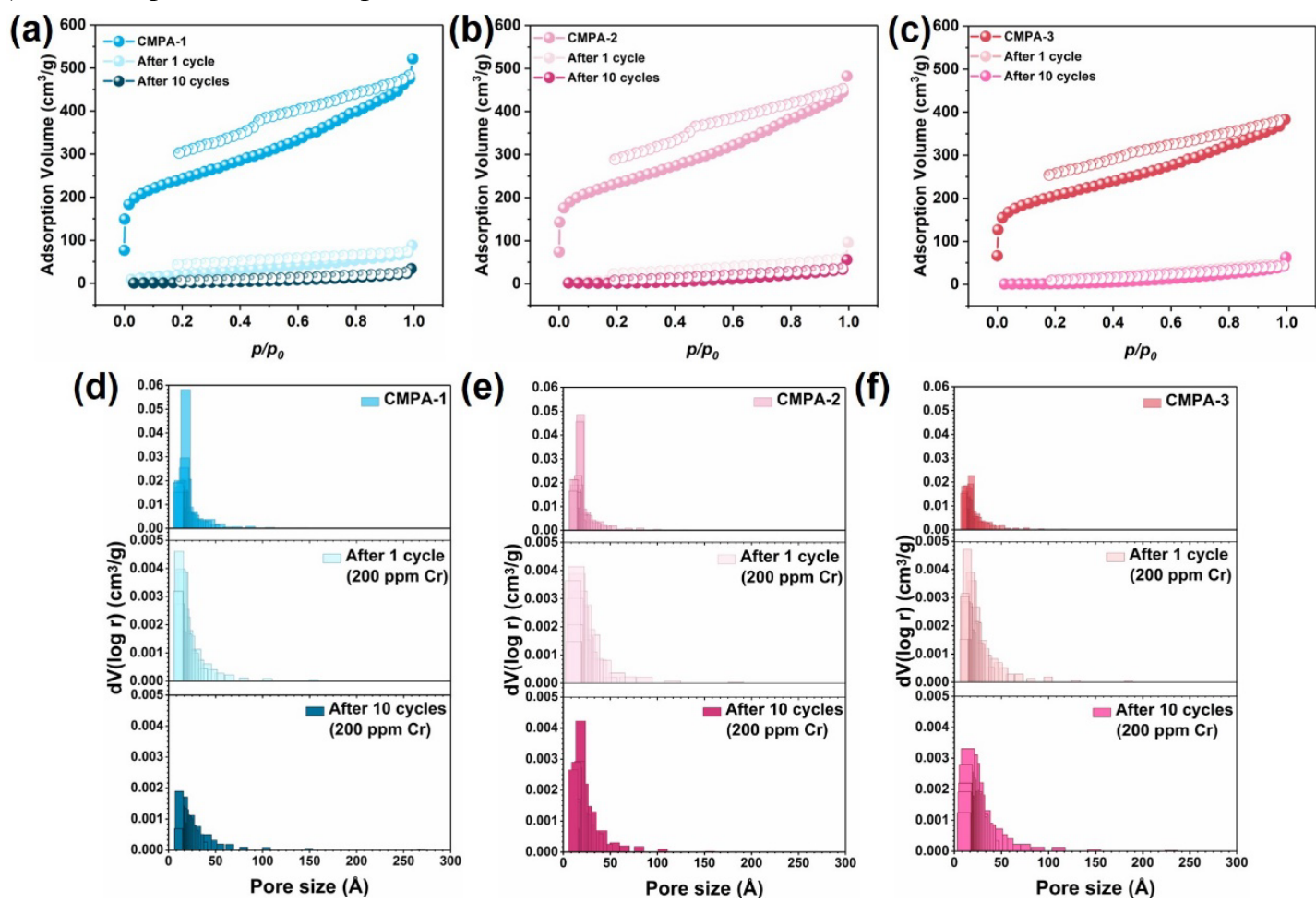

Figure $\mathbf{S 3 7} \mathrm{N}_{2}$ adsorption and desorption isotherm (CMPA-1, a; CMPA-2, b; CMPA-3, c) and BJH pore size distribution of the CMPA networks before and after 1 cycle and 10 cycles detoxication of Cr(VI) (CMPA-1, d; CMPA-2, e; CMPA-3, f). 
5) FTIR after cycling

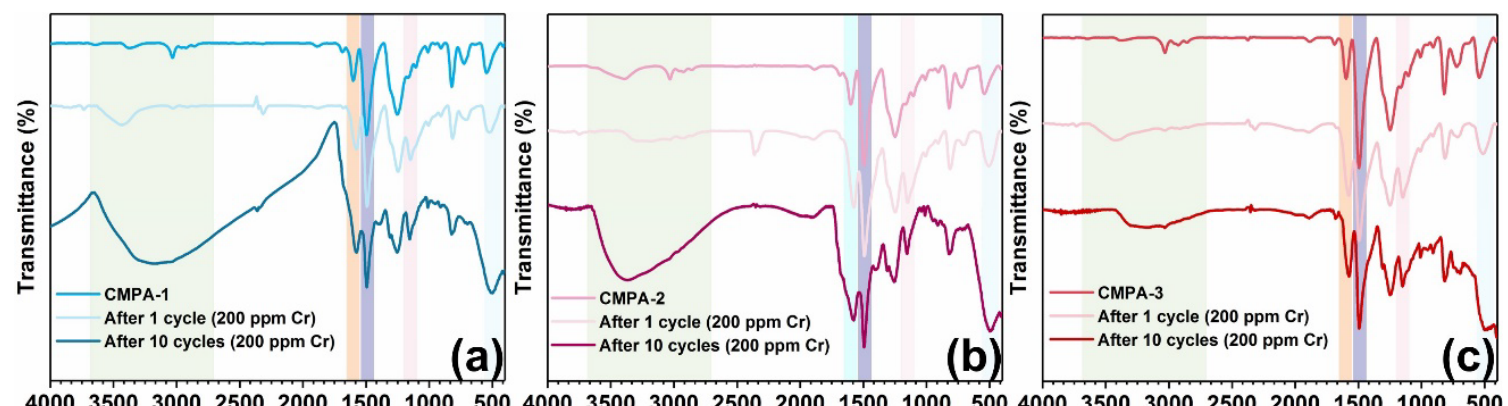

$40003500300025002000150010005004000350030002500200015001000 \quad 5004000 \quad 35003000250020001500 \quad 1000 \quad 500$ Wavenumber $\left(\mathrm{cm}^{-1}\right)$

Wavenumber $\left(\mathrm{cm}^{-1}\right)$

Wavenumber $\left(\mathrm{cm}^{-1}\right)$

Figure S38 FTIR spectra of the CMPA networks after 1 cycle and 10 cycles detoxication of $\mathrm{Cr}(\mathrm{VI})$. 

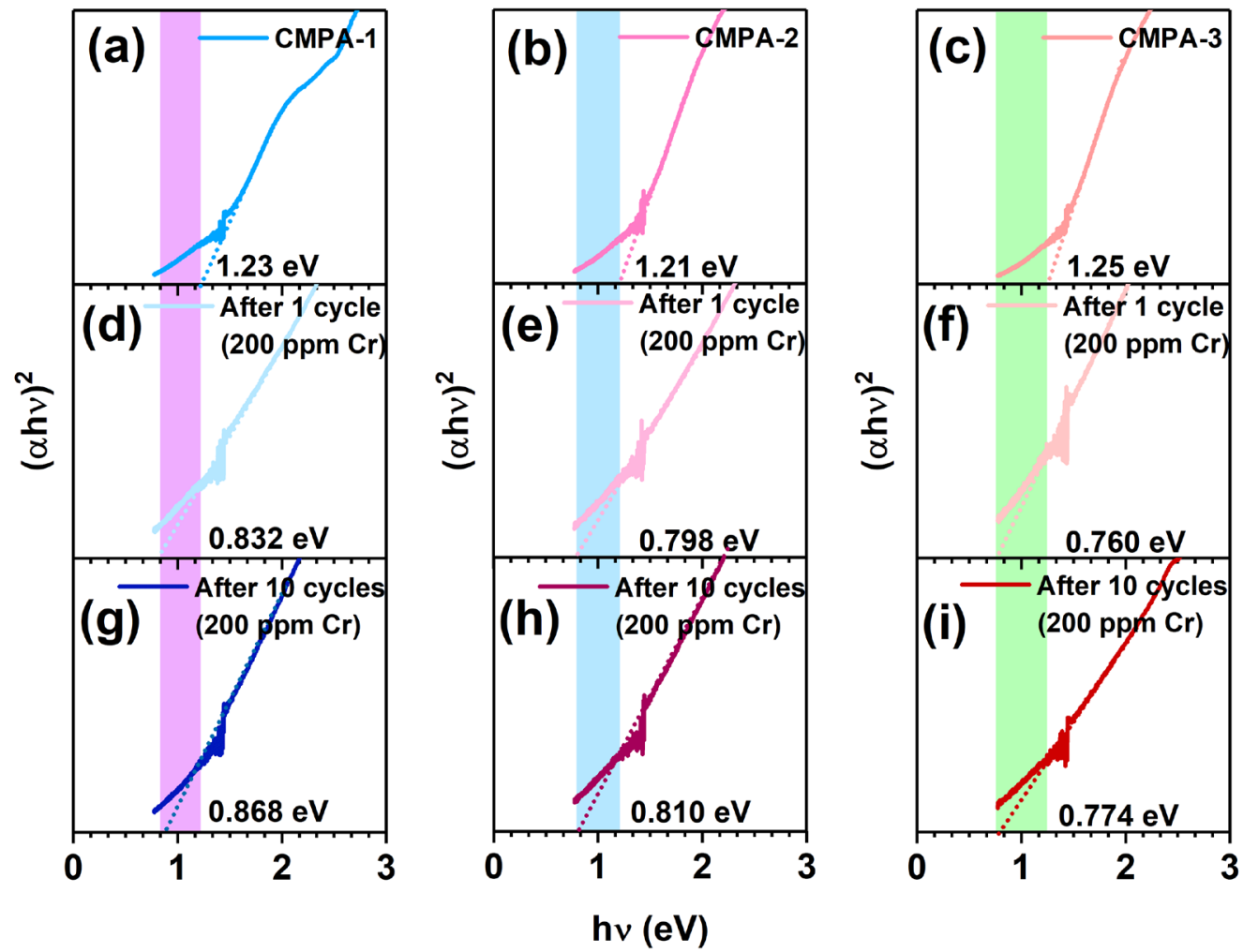

Figure S39 Changed solid-state UV/Vis diffuse-reflectance spectra of the CMPA networks after 1 cycle and 10 cycles detoxication of $\mathrm{Cr}(\mathrm{VI})(200 \mathrm{mg} / \mathrm{L})$. 
(2) $N_{2}$ adsorption and desorption isotherm after desorption
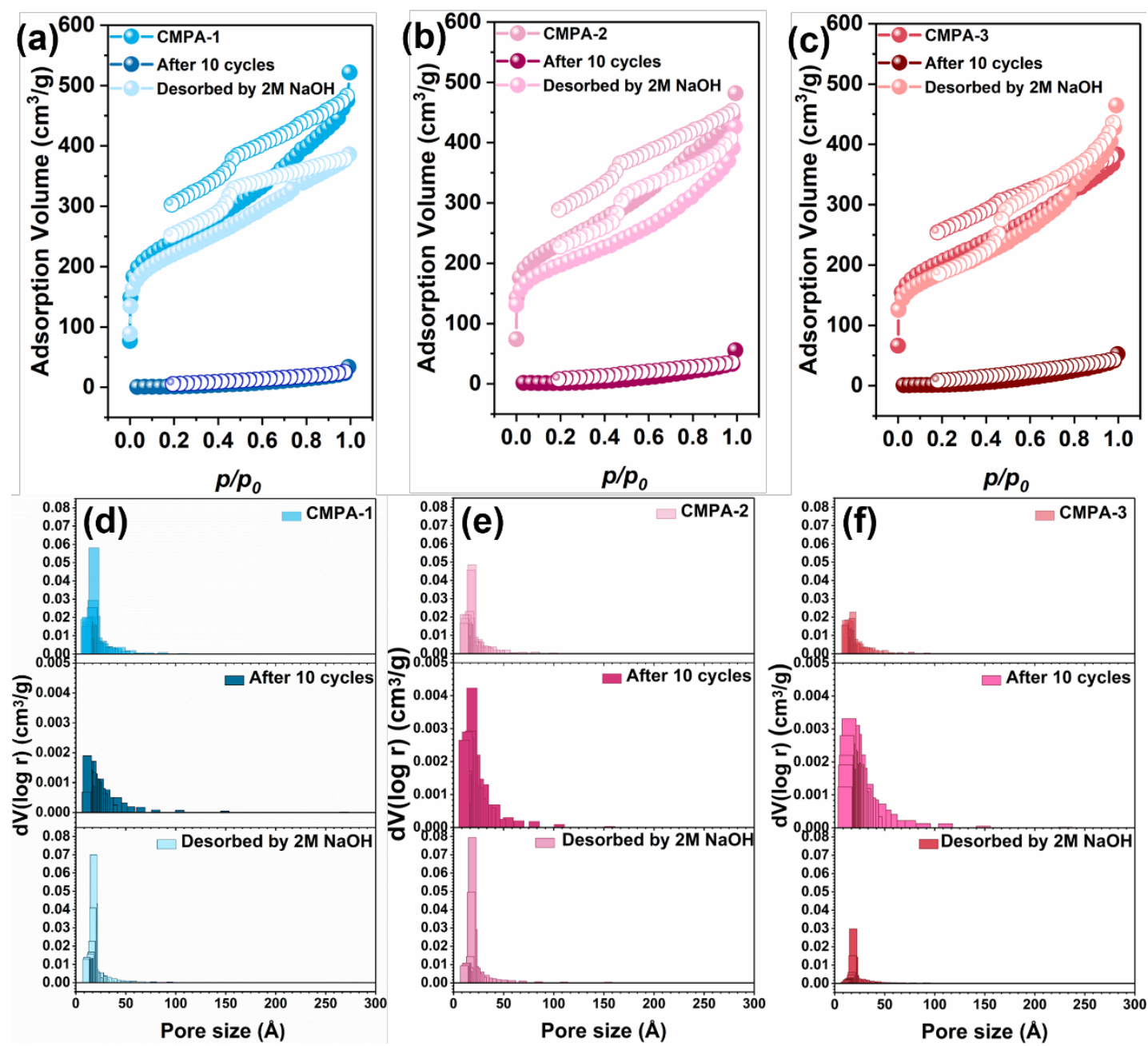

Figure $\mathbf{S 4 0} \mathrm{N}_{2}$ adsorption and desorption isotherm (CMPA-1, a; CMPA-2, b; CMPA-3, c) and BJH pore size distribution of the CMPA networks after 10 cycle treatment before and after desorption by $10 \mathrm{~mL}$ of $2 \mathrm{M} \mathrm{NaOH}$ (CMPA-1, d; CMPA-2, e; CMPA-3, f). 

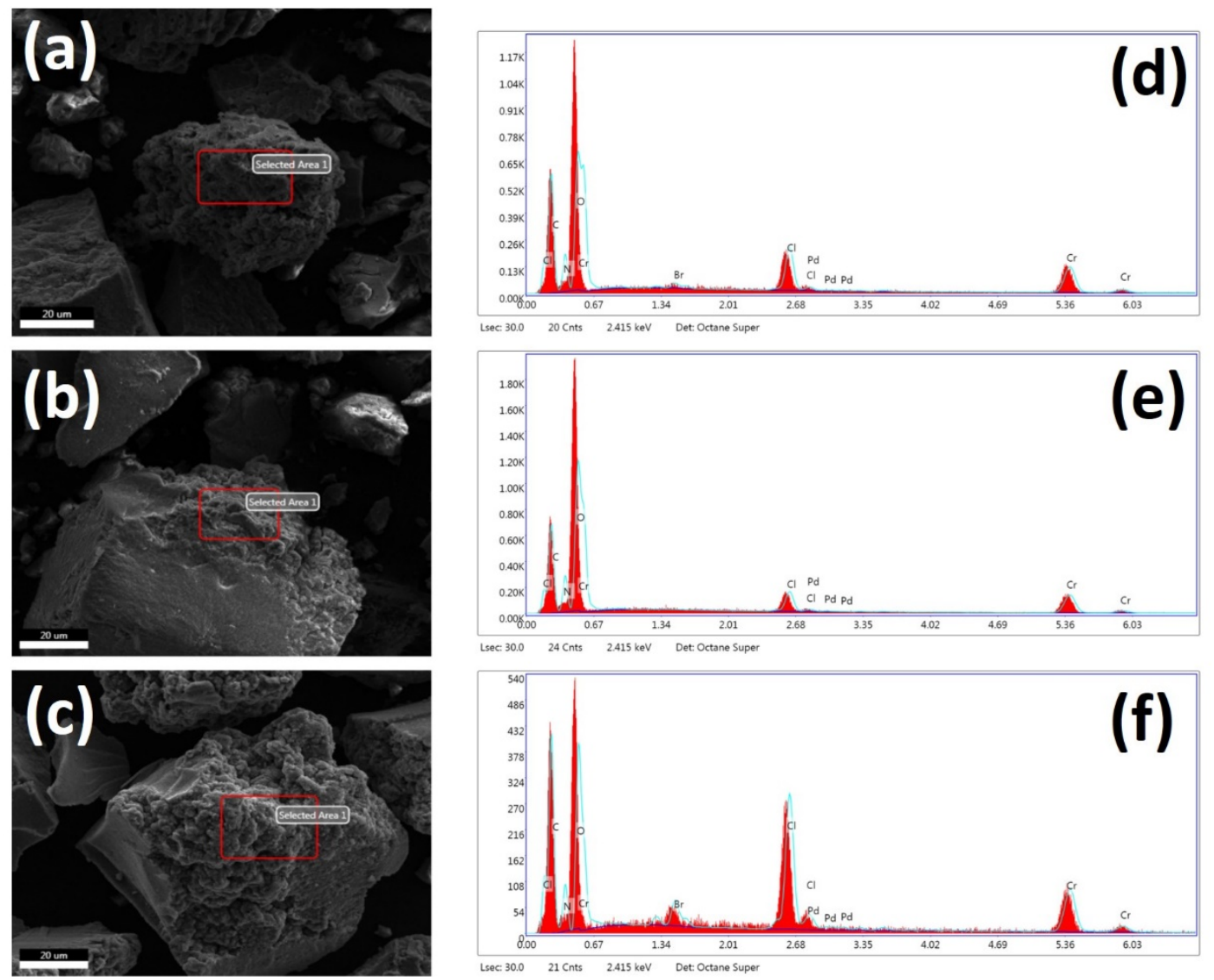

Figure S41 SEM photographs and elemental analysis of CMPA networks- CMPA-1 (a \& d), CMPA2 (b \& e) and CMPA-3 (c \& f) after 10 cycling use acquired from EDS (scale bar: $20 \mu \mathrm{m}$ ). 


\section{S3. Supplementary Tables}

Table S1 Detail information of XPS C 1s, O 1s and N 1s spectra of CMPA networks.

\begin{tabular}{|c|c|c|c|c|c|c|c|c|c|c|}
\hline & \multirow[b]{2}{*}{ Assignment } & \multicolumn{3}{|c|}{ CMPA-1 } & \multicolumn{3}{|c|}{ CMPA-2 } & \multicolumn{3}{|c|}{ СМРА-3 } \\
\hline & & $\begin{array}{c}\text { Peak } \\
\text { position/ } \\
\text { eV }\end{array}$ & Peak area & $\begin{array}{l}\text { Peak } \\
\text { ratio }\end{array}$ & $\begin{array}{c}\text { Peak } \\
\text { position/ } \\
\text { eV }\end{array}$ & Peak area & $\begin{array}{l}\text { Peak } \\
\text { ratio }\end{array}$ & $\begin{array}{c}\text { Peak } \\
\text { position/ } \\
\text { eV }\end{array}$ & Peak area & $\begin{array}{l}\text { Peak } \\
\text { ratio }\end{array}$ \\
\hline $\mathbf{N}$ & -NH- (amine) & 399.8 & 5224.2 & 0.477 & 399.8 & 1396.2 & 0.317 & 399.6 & 2863.9 & 0.469 \\
\hline \multirow{2}{*}{$\mathbf{C}$} & Graphitic C & 284.5 & 11265.2 & 0.148 & 284.5 & 31321.4 & 0.323 & 284.5 & 31695.1 & 0.311 \\
\hline & $\mathrm{C}=\mathrm{O} / \mathrm{C}-\mathrm{O}$ & - & - & - & 288.8 & 4560.1 & 0.047 & 288.9 & 3735.1 & 0.036 \\
\hline \multirow{2}{*}{$\mathbf{O}$} & $\mathbf{O}=\mathbf{C}$ & 532.1 & 6706.5 & 0.533 & 531.9 & 18777.8 & 0.430 & 532.1 & 13737.3 & 0.485 \\
\hline & $\mathrm{C}-\mathrm{O}$ & 533.6 & 5868.5 & 0.467 & 533.3 & 24875.5 & 0.570 & 533.3 & 14608.7 & 0.515 \\
\hline
\end{tabular}


Table S2 Elemental analysis of CMPA networks acquired from EDS.

\begin{tabular}{|c|c|c|c|c|c|c|c|c|c|c|c|}
\hline \multicolumn{4}{|c|}{ CMPA-1 } & \multicolumn{4}{|c|}{ CMPA-2 } & \multicolumn{4}{|c|}{ CMPA-3 } \\
\hline & $\begin{array}{c}\text { Weight } \\
\text { Percentage } \\
\%\end{array}$ & $\begin{array}{c}\text { Atomic } \\
\text { Percentage \% }\end{array}$ & $\begin{array}{c}\text { Error } \\
\%\end{array}$ & & $\begin{array}{c}\text { Weight } \\
\text { Percentage } \\
\%\end{array}$ & $\begin{array}{c}\text { Atomic } \\
\text { Percentage } \\
\%\end{array}$ & $\begin{array}{c}\text { Error } \\
\%\end{array}$ & & $\begin{array}{c}\text { Weight } \\
\text { Percentage } \\
\%\end{array}$ & $\begin{array}{c}\text { Atomic } \\
\text { Percentage } \\
\%\end{array}$ & $\begin{array}{c}\text { Error } \\
\%\end{array}$ \\
\hline C K & 84.97 & 88.71 & 3.03 & C K & 90.32 & 93.24 & 2.85 & C K & 75.74 & 86.05 & 5.40 \\
\hline N K & 9.07 & 8.12 & 33.83 & $\mathbf{N} \mathbf{K}$ & 5.95 & 5.26 & 44.89 & N K & 6.12 & 5.96 & 43.22 \\
\hline O K & 3.67 & 2.88 & 24.33 & O K & 1.57 & 1.22 & 49.10 & O K & 7.46 & 6.36 & 18.02 \\
\hline Br L & 0.75 & 0.12 & 28.94 & Br L & 0.53 & 0.08 & 61.69 & Br L & 6.24 & 1.07 & 12.48 \\
\hline Pd L & 1.54 & 0.18 & 30.18 & Pd L & 1.63 & 0.19 & 34.94 & Pd L & 4.44 & 0.57 & 30.60 \\
\hline
\end{tabular}


Table S3 Thermodynamic parameters of CMPA networks for $\mathrm{Cr}(\mathrm{VI})$ detoxication

\begin{tabular}{|c|c|c|c|c|}
\hline & $\Delta H(\mathrm{~kJ} / \mathrm{mol})$ & $\Delta S(\mathrm{~J} / \mathrm{mol} / \mathrm{K})$ & $T(K)$ & $\Delta G(\mathrm{~kJ} / \mathrm{mol})$ \\
\hline \multirow{4}{*}{ CMPA-1 } & \multirow{4}{*}{0.81} & \multirow{4}{*}{52.20} & 288 & -13.87 \\
\hline & & & 298 & -15.02 \\
\hline & & & 308 & -15.86 \\
\hline & & & 318 & -15.32 \\
\hline \multirow{4}{*}{ СМРА-2 } & \multirow{4}{*}{0.31} & \multirow{4}{*}{55.21} & 288 & -15.79 \\
\hline & & & 298 & -16.08 \\
\hline & & & 308 & -16.24 \\
\hline & & & 318 & -17.57 \\
\hline \multirow{4}{*}{ CMPA-3 } & \multirow{4}{*}{11.67} & \multirow{4}{*}{71.43} & 288 & -15.79 \\
\hline & & & 298 & -16.08 \\
\hline & & & 308 & -16.24 \\
\hline & & & 318 & -17.57 \\
\hline
\end{tabular}


Table S4 Kinetic parameters of CMPA networks for Cr(VI) detoxication with the effect of several co-existing ions, fitted with pseudo-first order and pseudo-second order kinetic model.

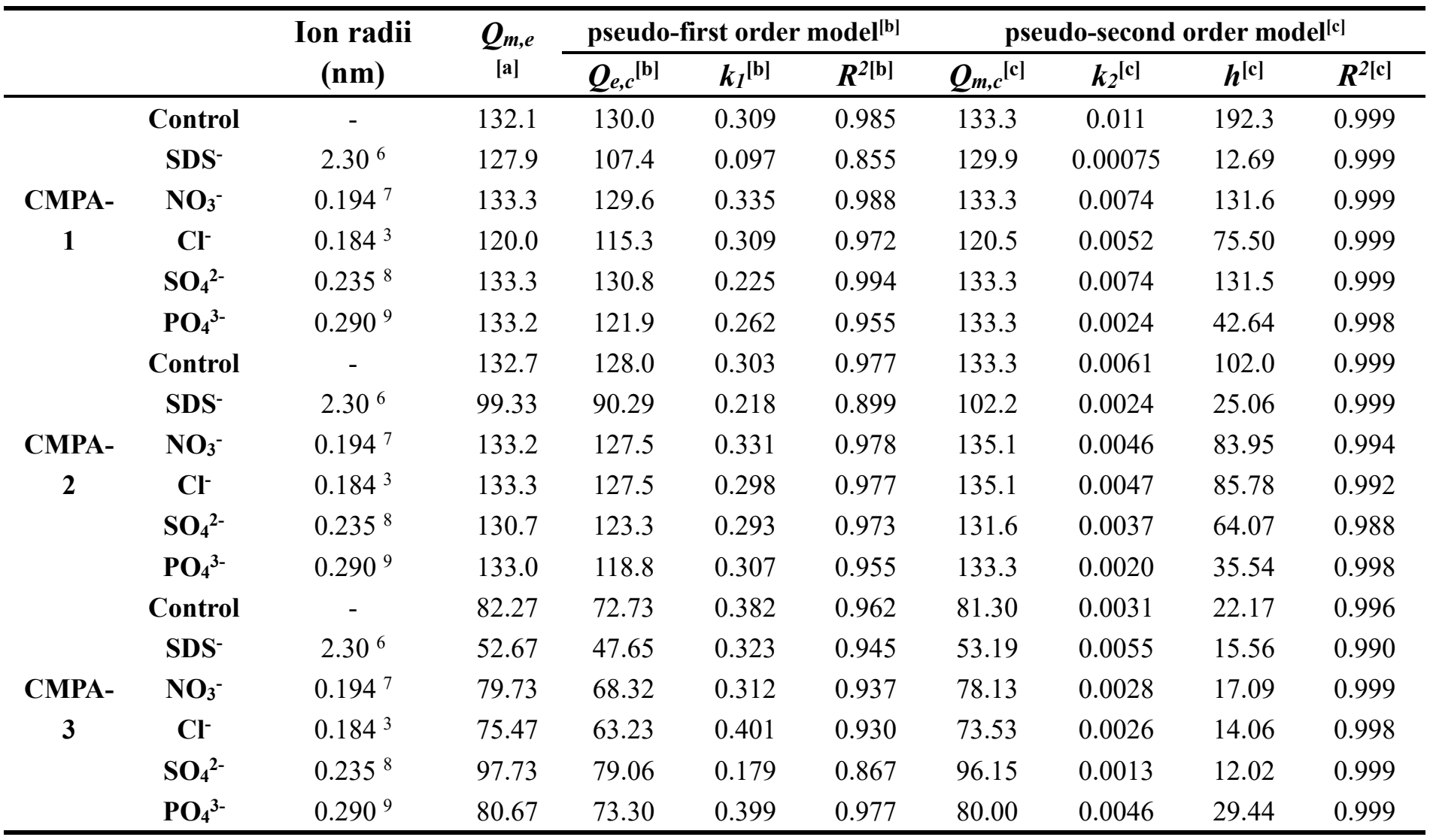

[a] $Q_{m, e}$ (maximum adsorption/detoxication capacity, $\mathrm{mg} / \mathrm{g}$ ) obtained from the kinetic experiment at its equilibrium state (at $180 \mathrm{~min}$ ), which can be calculated from the equation $Q_{m, e}=\left(c_{0}-c_{e}\right) \mathrm{V} / \mathrm{m}$, where $\mathrm{m}(\mathrm{mg})$ is the adsorbent mass, $V(\mathrm{~L})$ is the volume of $\mathrm{Cr}(\mathrm{VI})$ solution, $c_{0}$ and $c_{e}(\mathrm{mg} / \mathrm{L})$ are the $\mathrm{Cr}(\mathrm{VI})$ concentration at adsorption/detoxication time $t=0 \mathrm{~min}$ and $t=180 \mathrm{~min}$.

[b] The equation of pseudo-first order model is $Q_{t}=Q_{m, c}\left(1-\exp \left(-k_{1} t\right)\right)$, where $Q_{t}(\mathrm{mg} / \mathrm{g})$ is the adsorption/detoxication capacity of the CMPA networks at time $\mathrm{t}(\mathrm{min})$, which can be calculated from the equation $Q_{t}=\left(c_{0}-c_{t}\right) V / m$, where $\mathrm{m}(\mathrm{mg})$ is the adsorbent mass, $V(\mathrm{~L})$ is the volume of $\mathrm{Cr}(\mathrm{VI})$ solution, $c_{0}$ and $c_{t}(\mathrm{mg} / \mathrm{L})$ are the $\mathrm{Cr}(\mathrm{VI})$ concentration at adsorption/detoxication time $t=0 \mathrm{~min}$ and $t=$ $\mathrm{t} \min$, while $Q_{m, c}(\mathrm{mg} / \mathrm{g})$ is the maximum adsorption capacity calculated from the model. $k_{l}\left(\mathrm{~min}^{-1}\right)$ indicates the adsorption/detoxication constant of pseudo-first order model. $R^{2}$ suggests the regression constants.

[c] The equation of pseudo-second order model is $Q_{t}=k_{2} Q_{m, c}^{2} t /\left(1+k_{2} Q_{m, c} t\right) . k_{2}(\mathrm{~g} / \mathrm{mg} / \mathrm{min})$ indicates the adsorption/detoxication constant of pseudo-second order model. $R^{2}$ suggests the regression constants. $h(\mathrm{mg} / \mathrm{g} / \mathrm{min})$ is the initial adsorption/detoxication rate calculated from the equation below $h=k_{2} Q_{m, c}{ }^{2}$. 
Table S5 Porosity parameters of our CMPA networks after interaction with Cr(VI) with various initial concentrations.

\begin{tabular}{ccccc}
\hline & $\begin{array}{c}\boldsymbol{c}_{\boldsymbol{0}}(\mathbf{C r}(\mathbf{V I})) \\
(\mathbf{m g} / \mathbf{L})\end{array}$ & $\begin{array}{c}\text { Surface area } \\
\left(\mathbf{m}^{\mathbf{2}} / \mathbf{g}\right)\end{array}$ & $\begin{array}{c}\text { Total pore volume } \\
{[\mathbf{b ]}} \\
\left(\mathbf{c m}^{\mathbf{3}} / \mathbf{g}\right)\end{array}$ & $\begin{array}{c}\text { Micropore } \\
\text { volume }^{[\mathbf{c}]} \\
\left(\mathbf{c m}^{\mathbf{3}} / \mathbf{g}\right)\end{array}$ \\
\hline & 0 & 833 & 0.349 & 0.288 \\
CMPA-1 & 200 & 84 & 0.040 & 0.031 \\
& 1000 & 11 & 0.020 & 0.013 \\
& 0 & 750 & 0.340 & 0.286 \\
CMPA-2 & 200 & 35 & 0.039 & 0.026 \\
& 1000 & 8 & 0.030 & 0.019 \\
& 0 & 688 & 0.250 & 0.202 \\
CMPA-3 & 200 & 8 & 0.052 & 0.033 \\
& 1000 & 7 & 0.047 & 0.031 \\
\hline
\end{tabular}

[a] Surface area calculated from the $\mathrm{N}_{2}$ adsorption and desorption isotherm using the Brunauer-Emmett-Teller method. [b] The total pore volume acquired from the desorption branch of the $\mathrm{N}_{2}$ isotherm using the BJH method with all the pore volume calculated inside. [c] The micropore volume got from the desorption branch of the $\mathrm{N}_{2}$ isotherm using the BJH method with the volume of pore small than $2 \mathrm{~nm}$ (micropores) calculated inside. 
Table S6 Detail information of XPS N 1s spectra of CMPA networks after interaction with Cr(VI) with various concentrations.

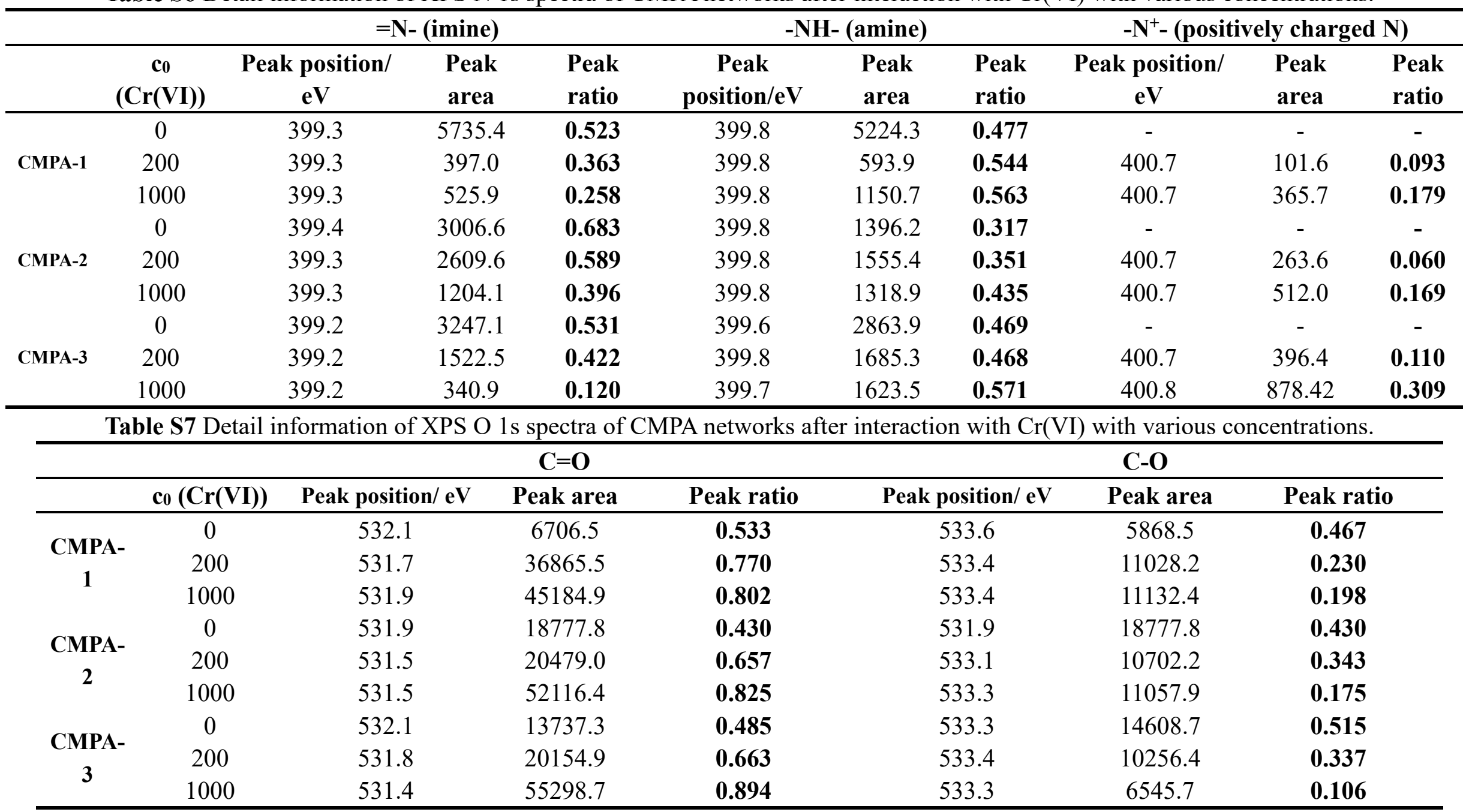


Table S8 Detail information of XPS C 1s spectra of CMPA networks after interaction with $\mathrm{Cr}(\mathrm{VI})$ with various concentrations.

\begin{tabular}{|c|c|c|c|c|c|c|c|c|c|c|c|c|c|}
\hline & & \multicolumn{3}{|c|}{ Graphitic C } & \multicolumn{3}{|c|}{ Imine } & \multicolumn{3}{|c|}{$\mathrm{C}-\mathrm{N}$} & \multicolumn{3}{|c|}{$\mathrm{C}=\mathrm{O} / \mathrm{C}-\mathrm{O}$} \\
\hline & $\begin{array}{c}c_{0} \\
(\operatorname{Cr}(V I))\end{array}$ & $\begin{array}{c}\text { Peak } \\
\text { position/ } \\
\text { eV }\end{array}$ & $\begin{array}{l}\text { Peak } \\
\text { area }\end{array}$ & $\begin{array}{l}\text { Peak } \\
\text { ratio }\end{array}$ & $\begin{array}{c}\text { Peak } \\
\text { position/ } \\
\text { eV }\end{array}$ & $\begin{array}{l}\text { Peak } \\
\text { area }\end{array}$ & $\begin{array}{l}\text { Peak } \\
\text { ratio }\end{array}$ & $\begin{array}{c}\text { Peak } \\
\text { position/ } \\
\text { eV }\end{array}$ & $\begin{array}{l}\text { Peak } \\
\text { area }\end{array}$ & $\begin{array}{l}\text { Peak } \\
\text { ratio }\end{array}$ & $\begin{array}{c}\text { Peak } \\
\text { position/ } \\
\text { eV }\end{array}$ & $\begin{array}{l}\text { Peak } \\
\text { area }\end{array}$ & $\begin{array}{l}\text { Peak } \\
\text { ratio }\end{array}$ \\
\hline \multirow{3}{*}{ CMPA-1 } & 0 & 284.5 & 11265.2 & 0.148 & 284.9 & 53493.9 & 0.705 & 285.9 & 11118.1 & 0.147 & - & - & - \\
\hline & 200 & 284.6 & 24841.2 & 0.417 & 285.0 & 20651.2 & 0.346 & 286.2 & 9779.5 & 0.164 & 288.8 & 4349.2 & 0.073 \\
\hline & 1000 & 284.4 & 26567.6 & 0.345 & 284.9 & 31376.0 & 0.407 & 286.0 & 13617.5 & 0.177 & 288.7 & 5510.7 & 0.071 \\
\hline \multirow{3}{*}{ CMPA-2 } & 0 & 284.5 & 31321.4 & 0.323 & 285.2 & 36047.1 & 0.372 & 285.5 & 24945.9 & 0.258 & 288.8 & 4560.1 & 0.047 \\
\hline & 200 & 284.5 & 17585.2 & 0.332 & 285.0 & 14571.5 & 0.276 & 285.6 & 17476.6 & 0.329 & 288.7 & 3257.3 & 0.063 \\
\hline & 1000 & 284.6 & 19644.9 & 0.393 & 285.1 & 15721.3 & 0.315 & 286.1 & 11382.0 & 0.228 & 288.7 & 3185.9 & 0.064 \\
\hline \multirow{3}{*}{ CMPA-3 } & 0 & 284.5 & 31695.1 & 0.311 & 285.0 & 33807.1 & 0.332 & 285.5 & 32706.0 & 0.321 & 288.9 & 3735.1 & 0.036 \\
\hline & 200 & 284.6 & 27088.9 & 0.404 & 285.0 & 27304.2 & 0.408 & 286.4 & 8431.8 & 0.126 & 288.8 & 4157.9 & 0.062 \\
\hline & 1000 & 284.5 & 10893.9 & 0.329 & 284.9 & 12369.1 & 0.375 & 286.1 & 7697.6 & 0.233 & 288.5 & 2127.3 & 0.063 \\
\hline
\end{tabular}


Table S9 Detail information of XPS N 1s spectra of CMPA networks after 1 cycle and 10 cycles detoxication of Cr(VI) (200 mg/L).

\begin{tabular}{|c|c|c|c|c|c|c|c|c|c|}
\hline & \multirow[b]{2}{*}{ Cycle time } & \multicolumn{3}{|c|}{$=\mathrm{N}-($ imine $)$} & \multicolumn{3}{|c|}{-NH- (amine) } & \multicolumn{2}{|c|}{$-\mathrm{N}^{+}$- (positively charged } \\
\hline & & Peak position/eV & Peak area & Peak ratio & Peak position/eV & $\begin{array}{c}\text { Peak } \\
\text { area }\end{array}$ & Peak ratio & Peak position/ eV & Peak area \\
\hline & 0 & 399.3 & 5735.4 & 0.523 & 399.8 & 5224.2 & 0.477 & - & - \\
\hline \multirow[t]{3}{*}{ CMPA-1 } & 1 & 399.3 & 397.0 & 0.363 & 399.8 & 593.9 & 0.544 & 400.7 & 101.6 \\
\hline & 10 & 399.3 & 1083.5 & 0.418 & 399.8 & 1161.9 & 0.448 & 400.7 & 345.3 \\
\hline & 0 & 399.4 & 3006.6 & 0.683 & 399.8 & 1396.2 & 0.317 & - & - \\
\hline \multirow[t]{3}{*}{ CMPA-2 } & 1 & 399.3 & 2609.6 & 0.589 & 399.8 & 1555.4 & 0.351 & 400.7 & 263.6 \\
\hline & 10 & 399.3 & 2325.0 & 0.609 & 399.8 & 1168.8 & 0.306 & 400.7 & 320.72 \\
\hline & 0 & 399.2 & 3247.1 & 0.531 & 399.6 & 2863.9 & 0.469 & - & - \\
\hline \multirow[t]{14}{*}{ CMPA-3 } & 1 & 399.2 & 1522.5 & 0.422 & 399.8 & 1685.3 & 0.468 & 400.7 & 396.4 \\
\hline & 10 & 399.3 & 1020.2 & 0.448 & 399.9 & 912.7 & 0.401 & 400.9 & 344.82 \\
\hline & \multicolumn{9}{|c|}{ Table S10 Detail information of XPS O 1s spectra of CMPA networks after 1 cycle and 10 cycles detoxication of Cr(VI) (200 mg/L). } \\
\hline & & & \multicolumn{3}{|c|}{$\mathbf{C}=\mathbf{O}$} & \multicolumn{4}{|c|}{ C-O } \\
\hline & & Cycle time & eak position/ eV & Peak area & Peak ratio & Peak & osition/ eV & Peak area & eak ratio \\
\hline & \multirow{4}{*}{ CMPA-1 } & 0 & 532.1 & 6706.5 & 0.533 & \multicolumn{2}{|c|}{533.6} & 5868.5 & 0.467 \\
\hline & & 1 & 531.7 & 36865.5 & 0.770 & \multicolumn{2}{|c|}{533.4} & 11028.2 & 0.230 \\
\hline & & 10 & 531.8 & 41611.3 & 0.795 & \multicolumn{2}{|c|}{533.4} & 10738.4 & 0.205 \\
\hline & & 0 & 531.9 & 18777.8 & 0.430 & \multicolumn{2}{|c|}{531.9} & 18777.7 & 0.430 \\
\hline & \multirow[t]{3}{*}{ CMPA-2 } & 1 & 531.5 & 20479.0 & 0.657 & \multicolumn{2}{|c|}{533.1} & 10702.2 & 0.343 \\
\hline & & 10 & 531.6 & 38188.1 & 0.815 & \multicolumn{2}{|c|}{533.3} & 8660.0 & 0.185 \\
\hline & & 0 & 532.1 & 13737.3 & 0.485 & \multicolumn{2}{|c|}{533.3} & 14608.7 & 0.515 \\
\hline & \multirow[t]{2}{*}{ CMPA-3 } & 1 & 531.8 & 20154.9 & 0.663 & \multicolumn{2}{|c|}{533.4} & 10256.4 & 0.337 \\
\hline & & 10 & 531.4 & 40984.8 & 0.846 & \multicolumn{2}{|c|}{533.3} & 7485.7 & 0.154 \\
\hline
\end{tabular}


Table S11 Detail information of XPS C 1s spectra of CMPA networks after 1 cycle and 10 cycles detoxication of Cr(VI) (200 mg/L).

\begin{tabular}{ccccccccccccccc}
\hline & \multicolumn{3}{c}{ Graphitic C } & \multicolumn{3}{c}{ Imine } & \multicolumn{3}{c}{ C-N } \\
\hline & $\begin{array}{c}\text { Cycle } \\
\text { time }\end{array}$ & $\begin{array}{c}\text { Peak } \\
\text { position/ } \\
\text { eV }\end{array}$ & $\begin{array}{c}\text { Peak } \\
\text { area }\end{array}$ & $\begin{array}{c}\text { Peak } \\
\text { ratio }\end{array}$ & $\begin{array}{c}\text { Peak } \\
\text { position/ } \\
\text { eV }\end{array}$ & $\begin{array}{c}\text { Peak } \\
\text { area }\end{array}$ & $\begin{array}{c}\text { Peak } \\
\text { ratio }\end{array}$ & $\begin{array}{c}\text { Peak } \\
\text { position/ } \\
\text { eV }\end{array}$ & $\begin{array}{c}\text { Peak } \\
\text { area }\end{array}$ & $\begin{array}{c}\text { Peak } \\
\text { ratio }\end{array}$ & $\begin{array}{c}\text { Peak } \\
\text { position/ eV }\end{array}$ & $\begin{array}{c}\text { Peak } \\
\text { area }\end{array}$ & $\begin{array}{c}\text { Peak } \\
\text { ratio }\end{array}$ \\
\hline & 0 & 284.5 & 11265.2 & $\mathbf{0 . 1 4 8}$ & 284.9 & 53493.9 & $\mathbf{0 . 7 0 5}$ & 285.9 & 11118.1 & $\mathbf{0 . 1 4 7}$ & - & - & - & \\
CMPA-1 & 1 & 284.6 & 24841.2 & $\mathbf{0 . 4 1 7}$ & 285.0 & 20651.2 & $\mathbf{0 . 3 4 6}$ & 286.2 & 9779.5 & $\mathbf{0 . 1 6 4}$ & 288.8 & 4349.2 & $\mathbf{0 . 0 7 3}$ \\
& 10 & 284.4 & 8677.5 & $\mathbf{0 . 1 2 3}$ & 284.8 & 40651.0 & $\mathbf{0 . 5 7 5}$ & 286.0 & 16901.6 & $\mathbf{0 . 2 3 9}$ & 288.7 & 4522.9 & $\mathbf{0 . 0 6 3}$ \\
& 0 & 284.5 & 31321.4 & $\mathbf{0 . 3 2 3}$ & 285.2 & 36047.1 & $\mathbf{0 . 3 7 2}$ & 285.5 & 24945.9 & $\mathbf{0 . 2 5 8}$ & 288.8 & 4560.1 & $\mathbf{0 . 0 4 7}$ \\
CMPA-2 & 1 & 284.5 & 17585.2 & $\mathbf{0 . 3 3 2}$ & 285.0 & 14571.5 & $\mathbf{0 . 2 7 6}$ & 285.6 & 17476.6 & $\mathbf{0 . 3 2 9}$ & 288.7 & 3257.3 & $\mathbf{0 . 0 6 3}$ \\
& 10 & 284.5 & 13377.3 & $\mathbf{0 . 2 5 2}$ & 284.8 & 24098.5 & $\mathbf{0 . 4 5 4}$ & 285.9 & 12437.5 & $\mathbf{0 . 2 3 4}$ & 288.7 & 3141.9 & $\mathbf{0 . 0 5 8}$ \\
& 0 & 284.5 & 31695.1 & $\mathbf{0 . 3 1 1}$ & 285.0 & 33807.1 & $\mathbf{0 . 3 3 2}$ & 285.5 & 32706.0 & $\mathbf{0 . 3 2 1}$ & 288.9 & 3735.1 & $\mathbf{0 . 0 3 6}$ \\
CMPA-3 & 1 & 284.6 & 27088.9 & $\mathbf{0 . 4 0 4}$ & 285.0 & 27304.2 & $\mathbf{0 . 4 0 8}$ & 286.4 & 8431.8 & $\mathbf{0 . 1 2 6}$ & 288.8 & 4157.9 & $\mathbf{0 . 0 6 2}$ \\
& 10 & 284.5 & 14318.3 & $\mathbf{0 . 3 6 3}$ & 284.9 & 12471.9 & $\mathbf{0 . 3 1 6}$ & 285.9 & 10355.2 & $\mathbf{0 . 2 6 2}$ & 288.7 & 2309.3 & $\mathbf{0 . 0 5 9}$ \\
\hline
\end{tabular}


Table S12 Porosity parameters of our CMPA networks after 1 cycle and 10 cycles detoxication of $\mathrm{Cr}(\mathrm{VI})(200 \mathrm{mg} / \mathrm{L})$.

\begin{tabular}{|c|c|c|c|c|}
\hline & Cycle time & $\begin{array}{l}\text { Surface area } \\
\qquad\left(\mathrm{m}^{2} / \mathrm{g}\right)\end{array}$ & $\begin{array}{c}\text { Total pore } \\
\text { volume } \\
\left(\mathrm{cm}^{3} / \mathrm{g}\right) \\
\end{array}$ & $\begin{array}{c}\text { Micropore } \\
\text { volume }^{[\mathrm{c}]} \\
\left(\mathrm{cm}^{3} / \mathrm{g}\right)\end{array}$ \\
\hline \multirow{4}{*}{ CMPA-1 } & 0 & 833 & 0.349 & 0.288 \\
\hline & 1 & 84 & 0.040 & 0.031 \\
\hline & 10 & 12 & 0.020 & 0.013 \\
\hline & Desorbed $^{[\mathrm{d}]}$ & 719 & 0.377 & 0.301 \\
\hline \multirow{3}{*}{ СМРА-2 } & 0 & 750 & 0.340 & 0.286 \\
\hline & 1 & 35 & 0.039 & 0.026 \\
\hline & 10 & 10 & 0.031 & 0.021 \\
\hline \multirow{5}{*}{ CMPA-3 } & Desorbed & 632 & 0.357 & 0.320 \\
\hline & 0 & 688 & 0.250 & 0.202 \\
\hline & 1 & 8 & 0.052 & 0.033 \\
\hline & 10 & 8 & 0.046 & 0.030 \\
\hline & Desorbed & 564 & 0.262 & 0.215 \\
\hline
\end{tabular}

[a] Surface area calculated from the $\mathrm{N}_{2}$ adsorption and desorption isotherm using the Brunauer-Emmett-Teller method. [b] The total pore volume acquired from the desorption branch of the $\mathrm{N}_{2}$ isotherm using the BJH method with all the pore volume calculated inside. [c] The micropore volume got from the desorption branch of the $\mathrm{N}_{2}$ isotherm using the BJH method with the volume of pore small than $2 \mathrm{~nm}$ (micropores) calculated inside. [d] Desorbed with $2 \mathrm{M} \mathrm{NaOH}$; desorption time: $3 \mathrm{~h}$; desorption temperature: $25^{\circ} \mathrm{C}$. 
Table S13 Elemental analysis of CMPA networks after 10 cycling use acquired from EDS.

\begin{tabular}{cccccccccc}
\hline & \multicolumn{3}{c}{ CMPA-1 } & \multicolumn{3}{c}{ CMPA-2 } & \multicolumn{3}{c}{ CMPA-3 } \\
\cline { 2 - 10 } Element & Weight \% & Atomic \% & Error \% & Weight \% & Atomic \% & Error \% & Weight \% & Atomic \% & Error \% \\
\hline $\mathbf{C}$ & 6.27 & 14.66 & 15.04 & 6.54 & 14.07 & 12.96 & 8.19 & 19.87 & 17.03 \\
$\mathbf{N}$ & 11.31 & 22.69 & 11.55 & 13.42 & 24.75 & 10.21 & 8.52 & 17.74 & 16.10 \\
$\mathbf{O}$ & 12.67 & 22.26 & 9.66 & 17.69 & 28.58 & 8.91 & 8.86 & 16.14 & 11.73 \\
$\mathbf{B r}$ & 1.06 & 0.37 & 41.23 & 0 & 0 & 0 & 3.04 & 1.11 & 22.23 \\
$\mathbf{C l}$ & 12.28 & 9.73 & 7.69 & 7.76 & 5.66 & 8.82 & 20.92 & 17.20 & 5.96 \\
$\mathbf{P d}$ & 0.78 & 0.21 & 62.32 & 0.67 & 0.16 & 62.62 & 1.28 & 0.35 & 57.34 \\
$\mathbf{C r}$ & 55.62 & 30.06 & 7.93 & 53.91 & 26.79 & 7.83 & 49.19 & 27.58 & 8.92 \\
\hline
\end{tabular}




\section{References}

(1) Jiang, J.-X.; Su, F.; Trewin, A.; Wood, C. D.; Niu, H.; Jones, J. T. A.; Khimyak, Y. Z.; Cooper, A. I. Synthetic Control of the Pore Dimension and Surface Area in Conjugated Microporous Polymer and Copolymer Networks. J. Am. Chem. Soc. 2008, 130 (24), 7710-7720, DOI: 10.1021/ja8010176.

(2) Jiang, J.-X.; Su, F.; Trewin, A.; Wood, C. D.; Campbell, N. L.; Niu, H.; Dickinson, C.; Ganin, A. Y.; Rosseinsky, M. J.; Khimyak, Y. Z.; Cooper, A. I. Conjugated Microporous Poly(aryleneethynylene) Networks. Angew. Chem. Int. Ed. 2007, 46 (45), 8574-8578, DOI: 10.1002/anie.200701595.

(3) Chen, J.; Yan, W.; Townsend, E. J.; Feng, J.; Pan, L.; Del Angel Hernandez, V.; Faul, C. F. J. Tunable Surface Area, Porosity, and Function in Conjugated Microporous Polymers. Angew. Chem. Int. Ed. 2019, 58 (34), 11715-11719, DOI: 10.1002/anie.201905488.

(4) Ghosal, P. S.; Gupta, A. K. Determination of Thermodynamic Parameters from Langmuir Isotherm Constant-Revisited. J. Mol. Liq. 2017, 225, 137-146, DOI: https://doi.org/10.1016/j.molliq.2016.11.058. (5) Kang, E. T.; Neoh, K. G.; Tan, K. L. Polyaniline: A Polymer with Many Interesting Intrinsic Redox States. Prog. Polym. Sci. 1998, 23 (2), 277-324, DOI: https://doi.org/10.1016/S0079-6700(97)00030-0. (6) Missel, P. J.; Mazer, N. A.; Benedek, G. B.; Young, C. Y.; Carey, M. C. Thermodynamic Analysis of the Growth of Sodium Ddodecyl Sulfate Micelles. J. Phys. Chem. 1980, 84 (9), 1044-1057, DOI: 10.1021/j100446a 021

(7) Li, X.; Wang, K.; Shen, M.; Wu, Z.; Xie, L. Thermodynamic Modeling of the $\mathrm{Ca}\left(\mathrm{NO}_{3}\right)_{2}-\mathrm{MNO}_{3}(\mathrm{M}$ : alkali metal) Systems. Calphad 2017, 59, 90-98, DOI: https://doi.org/10.1016/j.calphad.2017.08.004.

(8) Aramaki, K.; Mizoguchi, M.; Nishihara, H. Relationship Between the HSAB Principle and Effects of Various Anions and a Tetra-n-butylammonium Ion on Passive Film of Iron in a Borate Buffer Solution. J. Electrochem. Soc. 1991, 138 (2), 394-398, DOI: 10.1149/1.2085596.

(9) Giannimaras, E. K.; Koutsoukos, P. G. The Crystallization of Calcite in the Presence of Orthophosphate. J. Colloid Interface Sci. 1987, 116 (2), 423-430, DOI: https://doi.org/10.1016/00219797(87)90138-X. 